\title{
Antibody expressing pea seeds as fodder for prevention of gastrointestinal parasitic infections in chickens
}

\author{
Jana Zimmermann ${ }^{\dagger 1}$, Isolde Saalbach ${ }^{\dagger 1,2}$, Doreen Jahnn ${ }^{1}$, Martin Giersberg ${ }^{1}$, \\ Sigrun Haehnel ${ }^{1}$, Julia Wedel ${ }^{3}$, Jeanette Macek ${ }^{1,2}$, Karen Zoufal ${ }^{1}$, \\ Gerhard Glünder ${ }^{3}$, Dieter Falkenburg ${ }^{1}$ and Sergey M Kipriyanov*1,4
}

\begin{abstract}
Address: ${ }^{1}$ Novoplant GmbH, Am Schwabeplan 1b, 06466 Gatersleben, Germany, ${ }^{2}$ Leibniz-Institute of Plant Genetics and Crop Plant Research, Corrensstrasse 3, 06466 Gatersleben, Germany, ${ }^{3}$ Clinic for Poultry, University of Veterinary Medicine Hannover, Bünteweg 17, 30559 Hannover, Germany and ${ }^{4}$ Current address : Affitech AS, Oslo Research Park, Gaustadalléen 21, 0349 Oslo, Norway

Email: Jana Zimmermann - janawigger@hotmail.com; Isolde Saalbach - isolde@ipk-gatersleben.de; Doreen Jahn - doreen.jahn@glycotope.com; Martin Giersberg - giersberg@ipk-gatersleben.de; Sigrun Haehnel - sigrun.senger@gmx.de; Julia Wedel - wedel.julia@gmail.com; Jeanette Macek - macek@ipk-gatersleben.de; Karen Zoufal - k.zoufal@web.de; Gerhard Glünder - gerhard.gluender@tiho-hannover.de; Dieter Falkenburg - falkenburg@naturin.viscofan.com; Sergey M Kipriyanov* - s.kiprijanov@affitech.com

* Corresponding author †Equal contributors
\end{abstract}

Published: II September 2009

BMC Biotechnology 2009, 9:79 doi:10.1 186/1472-6750-9-79
Received: 15 May 2009

Accepted: II September 2009

This article is available from: http://www.biomedcentral.com/I472-6750/9/79

(c) 2009 Zimmermann et al; licensee BioMed Central Ltd.

This is an Open Access article distributed under the terms of the Creative Commons Attribution License (http://creativecommons.org/licenses/by/2.0), which permits unrestricted use, distribution, and reproduction in any medium, provided the original work is properly cited.

\begin{abstract}
Background: Coccidiosis caused by protozoans of genus Eimeria is a chicken parasitic disease of great economical importance. Conventional disease control strategies depend on vaccination and prophylactic use of anticoccidial drugs. Alternative solution to prevent and treat coccidiosis could be provided by passive immunization using orally delivered neutralizing antibodies. We investigated the possibility to mitigate the parasitic infection by feeding poultry with antibody expressing transgenic crop seeds.

Results: Using the phage display antibody library, we generated a panel of anti-Eimeria scFv antibody fragments with high sporozoite-neutralizing activity. These antibodies were expressed either transiently in agrobacteria-infiltrated tobacco leaves or stably in seeds of transgenic pea plants. Comparison of the scFv antibodies purified either from tobacco leaves or from the pea seeds demonstrated no difference in their antigen-binding activity and molecular form compositions. Force-feeding experiments demonstrated that oral delivery of flour prepared from the transgenic pea seeds had higher parasite neutralizing activity in vivo than the purified antibody fragments isolated from tobacco. The pea seed content was found to protect antibodies against degradation by gastrointestinal proteases (>100-fold gain in stability). Ad libitum feeding of chickens demonstrated that the transgenic seeds were well consumed and not shunned. Furthermore, feeding poultry with shred prepared from the antibody expressing pea seeds led to significant mitigation of infection caused both by high and low challenge doses of Eimeria oocysts.
\end{abstract}

Conclusion: The results suggest that our strategy offers a general approach to control parasitic infections in production animals using cost-effective antibody expression in crop seeds affordable for the animal health market. 


\section{Background}

Coccidiosis is a diarrheal disease of chickens caused by protozoan parasites of the genus Eimeria. It impairs mortality, feed utilization and growth of poultry and causes annual losses of US $\$ 2.4$ billion to the poultry industry worldwide [1]. Conventional disease control strategies depend on vaccination and prophylactic use of anticoccidial drugs. However, resistances against the anticoccidial compounds have already spread and coccidiostats as feed additives will be banned in Europe by the year 2012 [2]. Vaccination strategies with avirulent or attenuated Eimeria strains have been routinely used for 50 years, but the large scale production of parasites is relatively laborious and expensive. Limited progress has been achieved towards the development of subunit or recombinant vaccines, the major hurdle being the identification of protective antigens and the delivery (presentation) of the recombinant vaccine to the chicken immune system $[1,3,4]$.

As an alternative strategy, coccidiosis could be prevented by oral delivery of antibodies that inhibit parasite invasion. The complex life cycle of Eimeria comprises an exogenous phase in the environment during which the excreted oocysts undergo sporulation. After infection via ingestion of sporulated oocysts, an endogenous phase in the chicken intestine consisting of asexual reproduction (schizogony) and sexual differentiation (gamogony) takes place, followed by fertilization and shedding of unsporulated oocysts [5]. The key step in the disease process in the chicken is the invasion of gut epithelial cells by the parasite. Gut epithelium invasion is accomplished by sporozoites and merozoites as the extracellular invasive stages which represent an attractive target for orally applied inhibitory antibodies. During the last years, numerous monoclonal antibodies against Eimeria antigens have been generated, several of them showed an inhibitory effect on sporozoite invasion in the cell culture [6-8]. Furthermore, some monoclonal antibodies, administered intravenously (i.v.) or intraperitoneally (i.p.) for passive immunization, were able to reduce significantly the oocyst output and/or the lesion scores in the chicken gut $[9,10]$.

There are a few major issues precluding use of monoclonal antibodies for preventive and curative passive immunization of the animals against infectious diseases: (i) the costs of antibody production and (ii) the costs of treatment. The treatment costs could be significantly reduced by switching from i.v. or i.p. route of administration to the oral delivery of the feed additives. However, (iii) the natural antibodies per se are the serum proteins which easily degrade in the gastrointestinal (GI) tract before they reach their target. All mentioned issues have been addressed in the present study. Using a phage display antibody library, we generated the anti-Eimeria anti- body fragments with high sporozoite-neutralizing activity. These antibodies were expressed in seeds of transgenic feed pea thus providing a cost-effective antibody production platform affordable for the animal health market. The pea seeds demonstrated the excellent antibody storage properties: dry seeds could be stored at room temperature for long time periods without any loss of antibody activity and they could withstand elevated temperatures during the preparation of feed pellets. Moreover, pea seed content protects antibodies from degradation in the GI tract. The animal experiments demonstrated that ad libitum feeding of chickens with fodder comprising the shred prepared from the antibody expressing pea seeds led to a protective and/or curative effect on infection of chickens with Eimeria parasite.

\section{Results \\ Generation of a phage display antibody library and selection of Eimeria-specific antibodies}

To generate recombinant antibodies with Eimeria parasite-neutralizing activity, mice were immunized with a mixture containing purified parasite material (oocysts, sporocysts and sporozoites) of five avian Eimeria species (E. tenella, E. acervulina, E. necatrix, E. maxima and E. brunetti). Spleens of mice with the positive immune response were used for mRNA extraction and generation of phage displayed singe-chain $\mathrm{Fv}(\mathrm{scFv})$ antibody library of diversity $5.5 \times 10^{7}$ individual clones. For isolation of antibody fragments binding to Eimeria proteins, soluble protein extracts of oocysts, sporozoites and merozoites of $E$. tenella (one of the most economically important Eimeria species [1]) were used as complex antigens for panning of the scFv library. After three rounds of panning, amplification, and re-panning, 112 clones expressing scFv were obtained that bound the oocyst extract, 64 clones which bound sporozoite protein, 39 clones that bound membrane proteins from oocysts and sporozoites and 67 clones that bound merozoite proteins (Table 1). Sequence analyses revealed that the selected clones comprise 97 individual scFvs. ELISA demonstrated specific binding of all 97 selected $\mathrm{scFv}$ variants to immobilized Eimeria antigens with signals significantly higher than the background; 55 scFvs bound to oocyst proteins, 58 to sporozoite proteins and 22 to merozoite proteins. Some scFvs showed specificity to both oocyst and sporozoite or merozoite proteins, thus indicating that the recognized antigens are expressed in different live forms of the parasite (Table 1).

\section{Identification of scFv antibodies that inhibit invasion of Eimeria tenella}

To identify scFvs that interfere with sporozoite invasion, $28 \mathrm{scFv}$ variants binding to oocyst extracts were selected for further analyses, since they demonstrated distinct sequence variations mainly localized in the complementarity determining regions (CDR). For selection of anti- 
Table I: Antibody variants selected by screening of an anti-Eimeria scFv library using complex antigens from $E$. tenella.

\begin{tabular}{|c|c|c|c|c|c|c|}
\hline \multirow[t]{2}{*}{$\begin{array}{c}\text { scFv } \\
\text { nomenclature }\end{array}$} & \multirow[t]{2}{*}{$\begin{array}{l}\text { Antigen used for } \\
\text { screening }\end{array}$} & \multirow[t]{2}{*}{$\begin{array}{c}\text { Number of } \\
\text { selected clones }\end{array}$} & \multirow[t]{2}{*}{$\begin{array}{l}\text { Number of } \\
\text { unique clones }\end{array}$} & \multicolumn{3}{|c|}{$\begin{array}{l}\text { Unique clones showing cross-reactivity with the } \\
\text { antigen }\end{array}$} \\
\hline & & & & Oocyst extract & $\begin{array}{l}\text { Sporozoite } \\
\text { extract }\end{array}$ & $\begin{array}{l}\text { Merozoite } \\
\text { extract }\end{array}$ \\
\hline$A A$ & Oocyst extract & 112 & 37 & 37 & 23 & 0 \\
\hline$A B$ & Sporozoite extract & 64 & 35 & 15 & 35 & n.t. \\
\hline$A C$ & $\begin{array}{l}\text { Oocyst and } \\
\text { sporozoite } \\
\text { membrane proteins }\end{array}$ & 39 & 3 & 0 & n.t. & 0 \\
\hline$A D, A E, A F$ & Merozoite extract & 67 & 22 & 3 & n.t. & 22 \\
\hline
\end{tabular}

n.t., not tested.

body fragments interfering with cell infection by parasite, the sporozoite invasion assay in vitro has been chosen. The method is based on observation that certain cultured mammalian cells, such as Madin-Darby bovine kidney (MDBK) epithelial cells, are susceptible to invasion by sporozoites of E. tenella even though these cells are not natural hosts for this parasite. Accordingly, the antibodies specifically binding sporozoite antigens involved in cell invasion can protect the cells from the Eimeria infection [11] (Figure 1a). For each scFv, at least two independent invasion inhibition assays were performed. These "activity-screens" were set up to detect any scFv with evidence of inhibitory activity. The threshold that was defined for inhibitory activity was $\mathrm{a}=10 \%$ reduction of intracellular sporozoites in both independent experiments. This requirement was met by six out of the 28 tested scFvs
(Table 2). The scFv inhibition of sporozoite invasion was found to be dose-dependent, as demonstrated by titration of purified antibody fragments (Figure $1 \mathrm{~b}, \mathrm{c}$ ).

\section{Analyses of binding properties, antigen- and species- specificity of parasite-neutralizing scFvs}

A detailed analysis of the antigen specificity of six selected antibody fragments with proven ability to inhibit cell invasion of E. tenella sporozoites (AA19, AA28, AB09, $\mathrm{AB} 21, \mathrm{AB} 28$ and $\mathrm{AD} 10)$ was performed using ELISA, Western blot analysis, flow cytometry and indirect fluorescent antibody test (IFAT). For this purpose, the complex antigens were prepared from different live forms of the $E$. tenella parasites. In addition, a number of known most probable antigen candidates, such as immunodominant surface antigen EtSAG1 (TA4) [12]; microneme proteins

Table 2: Invasion inhibition activity and antigen specificity of the selected scFvs.

\begin{tabular}{|c|c|c|c|c|c|c|c|c|}
\hline \multirow[t]{2}{*}{ scFv } & \multirow[t]{2}{*}{$\begin{array}{l}\text { Inhibition of } \\
\text { invasion (\%)' }\end{array}$} & \multicolumn{3}{|c|}{ Binding to complex antigens ${ }^{2}$} & \multicolumn{2}{|c|}{$\begin{array}{l}\text { Putative mol. weight of recognized } \\
\text { antigen }(\mathrm{kDa})^{3}\end{array}$} & \multicolumn{2}{|c|}{ Sporozoite surface binding ${ }^{4}$} \\
\hline & & $\begin{array}{l}\text { Oocyst } \\
\text { extract }\end{array}$ & $\begin{array}{l}\text { Sporozoite } \\
\text { extract }\end{array}$ & $\begin{array}{l}\text { Merozoite } \\
\text { extract }\end{array}$ & Reduced & Non-reduced & FACS & IFAT \\
\hline $\mathrm{AA} 19$ & $28 \pm 14$ & + & - & - & $83-175$ & $83-175$ & - & - \\
\hline AA28 & $36 \pm 16$ & + & - & - & $100-150$ & $100-150$ & - & - \\
\hline AB09 & $52 \pm 15$ & + & + & - & n.d. & $15-20$ & + & + \\
\hline$A B 2 I$ & $32 \pm 7$ & + & + & - & n.d. & $15-20$ & + & + \\
\hline AB28 & $25 \pm 3$ & + & + & - & Negative & $15-20$ & + & + \\
\hline ADIO & $36 \pm 12$ & + & + & - & Negative & $15-20$ & + & + \\
\hline
\end{tabular}

I In each experiment, $10 \mu \mathrm{g}$ bacterially expressed and purified scFv was used. Means and SDs of triplicates are shown.

${ }^{2}$ As determined by ELISA.

${ }^{3}$ As estimated by comparison with molecular weight markers in Western blot analyses.

${ }^{4}$ As determined by IFAT and flow cytometry (FACS).

+, binding; -, no binding; n.d., not determined. 
(a)

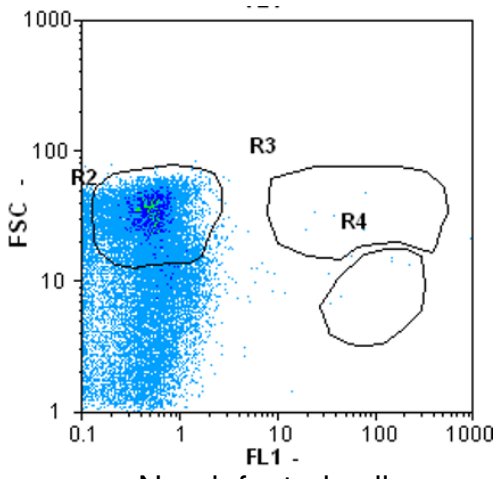

Non-infected cells

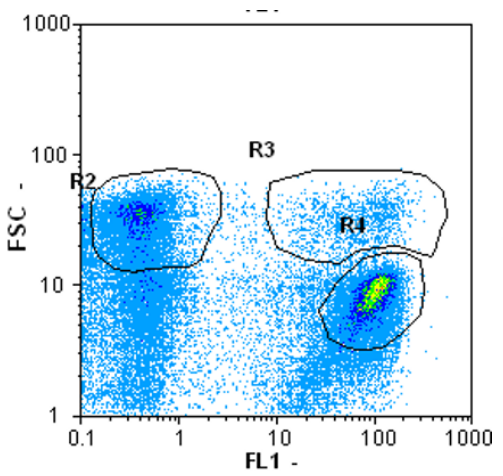

Infected cells (negative control)

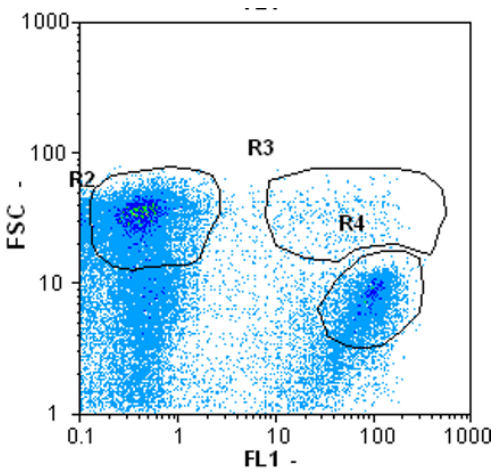

Cells infected in presence of scFv AB28

(b)

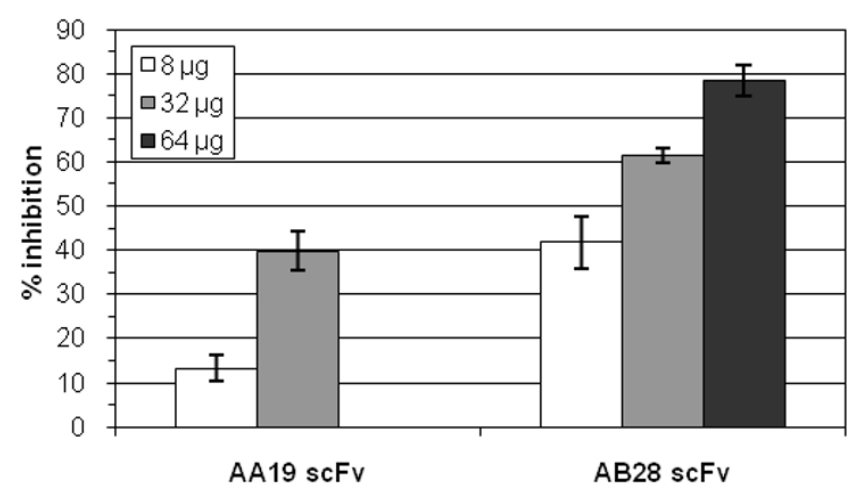

(c)

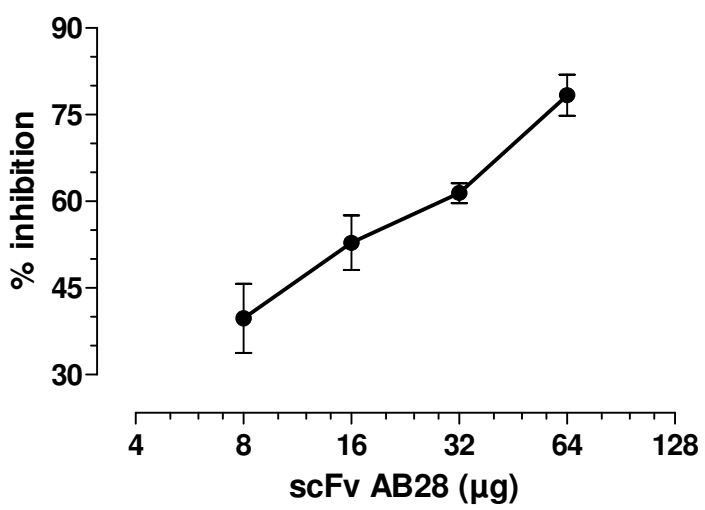

(d)

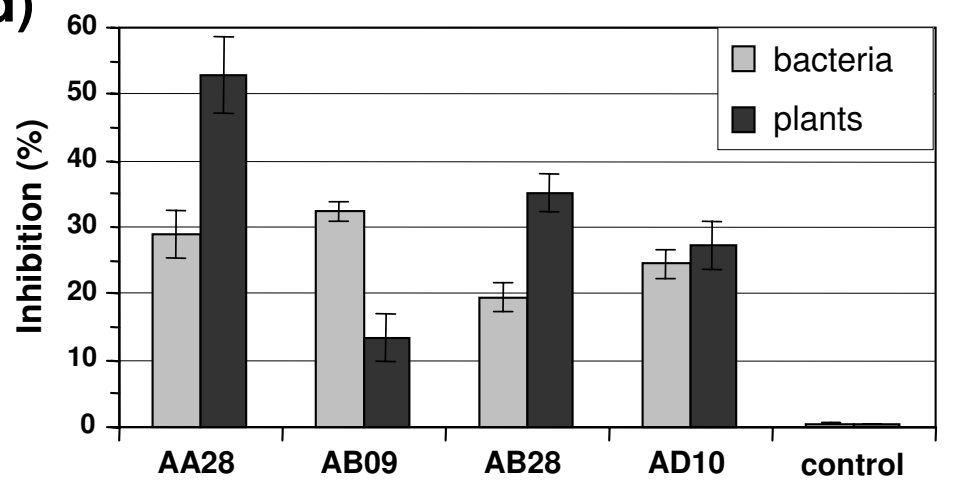

Figure I

Inhibition of sporozoite invasion in vitro by anti-Eimeria scFvs. (a) Analyses of Eimeria-infected cells by flow cytometry. Left panel, no infection; middle panel, infected cells (negative control); right panel, infection with sporozoites preincubated with inhibitory scFv AB28 at a concentration of $5.2 \mu \mathrm{M}$. In this example, 78\% inhibition was observed. (b) Comparison of the inhibitory activity of scFvs AAI 9 and AB28. (c) Dose-dependent inhibition of sporozoite invasion in vitro by scFv AB28. (d) Comparison of anti-sporozoite activity in vitro of scFv fragments $(10 \mu \mathrm{g})$ produced in bacteria or in tobacco leaves. Control, buffer alone. 
EtMic1 [13], EtMic2 [14], EtMic3 [11] and EtMic5 [15]; Eimepsin (aspartyl proteinase) [16]; merozoite antigen MZP 5-7 [17] and a $19 \mathrm{kDa}$ antigen 3-1E (potential immunostimulator) [18] were generated and expressed as recombinant proteins. Since the EtSAG1 antigen as isolated from the parasite is composed of a $17 \mathrm{kDa}$ polypeptide (large subunit) and a $8 \mathrm{kDa}$ polypeptide (small subunit) linked by a disulfide bridge [12], recombinant EtSAG1 protein was produced in bacteria as a $25 \mathrm{kDa}$ precursor without a signal peptide and a glycosylphosphatidylinositol (GPI) anchor. The results of analyses are summarized in Tables 2 and 3. Out of six tested, four scFv candidates (AB09, AB21, AB28 and AD10) demonstrated clear staining of the surface of E. tenella sporozoites (Table 2; Figure 2). Moreover, these four variants showed specific binding to the recombinant EtSAG1 precursor (Table 3; Figure 3a). SDS-PAGE and Western blot analyses revealed that all EtSAG1-specific scFvs (AB09, AB21, AB28 and $\mathrm{AD} 10)$ recognized the large $17 \mathrm{kDa}$ subunit of EtSAG1 in oocyst and sporozoite extracts of E. tenella under nonreducing conditions (Table 2; Figure 3a). In contrast, no antibody binding was detected when the oocyst extract was reduced (Table 2; Figure 3a). Interestingly, the EtSAG1-specific scFvs retained binding to the $25 \mathrm{kDa}$ precursor also under reducing conditions.

For analysis of cross-reactivity of the $\mathrm{scFv}$ fragments selected for inhibition of invasion of E. tenella sporozoites with other Eimeria species, the complex soluble antigens were prepared from sporulated oocysts of three avian Eimeria species (E. tenella, E. acervulina and E. brunetti) and two rodent Eimeria species (E. nieschulzi and E. papillata). As expected, all EtSAG1-specific scFvs showed reactivity only with E. tenella (Table 3 ). The $s c F v$ variants $\mathrm{AB} 09, \mathrm{AB} 21, \mathrm{AB} 28$ and $\mathrm{AD} 10$ did not interact with the protein preparations from other species, thus indicating that they recognize EtSAG1 epitopes which are unique for E. tenella. In contrast, the scFvs AA19 and AA28 demon-

Table 3: Antigen and species specificity of the selected scFvs with anti-sporozoite invasion activity, as determined by ELISA (E) and Western blot analyses (W).

\begin{tabular}{|c|c|c|c|c|c|c|c|c|}
\hline \multirow[t]{2}{*}{ scFv } & \multicolumn{8}{|c|}{ Recombinant antigen } \\
\hline & EtSAG I & EtMicl & EtMic2 & EtMic3 & EtMic5 & Eimepsin & MZP 5-7 & 19 kDa Ag \\
\hline AAI9 & $-(E)$ & $-(W)$ & $-(E)$ & $-(W)$ & $-(W)$ & $-(\mathrm{W})$ & $-(\mathrm{E})$ & $-(E)$ \\
\hline AA28 & $-(E)$ & $-(W)$ & $-(E)$ & $-(W)$ & $-(W)$ & $-(W)$ & $-(E)$ & $-(E)$ \\
\hline AB09 & $+(E, W)$ & $-(W)$ & $-(E)$ & $-(W)$ & $-(W)$ & $-(W)$ & $-(E)$ & $-(E)$ \\
\hline$A B 21$ & $+(\mathrm{E})$ & n.t. & $-(E)$ & n.t. & n.t. & n.t. & $-(\mathrm{E})$ & $-(E)$ \\
\hline AB28 & $+(E, W)$ & $-(W)$ & $-(E)$ & $-(W)$ & $-(W)$ & $-(W)$ & $-(\mathrm{E})$ & $-(E)$ \\
\hline ADIO & $+(E, W)$ & n.t. & n.t. & n.t. & n.t. & n.t. & n.t. & $-(E)$ \\
\hline
\end{tabular}

\begin{tabular}{cccccc}
\hline \multirow{2}{*}{$s c F v$} & \multicolumn{5}{c}{ Eimeria species } \\
\cline { 2 - 6 } & E. tenella & E. acervulina & E. brunetti & E. papillata & E. nieschulzi \\
\hline$A A 19$ & $+(E, W)$ & $+(E, W)$ & $+(E)$ & $+(E)$ & $-(E)$ \\
\hline$A A 28$ & $+(E, W)$ & $+(E, W)$ & $+(E, W)$ & $+(E)$ & $-(E)$ \\
\hline$A B 09$ & $+(E, W)$ & $-(E, W)$ & $-(E)$ & $-(E)$ & $-(E)$ \\
\hline$A B 21$ & $+(E, W)$ & $-(E, W)$ & $-(E)$ & $-(E)$ & $-(E)$ \\
\hline$A B 28$ & $+(E, W)$ & $-(E, W)$ & $-(E, W)$ & $-(E)$ & $-(E)$ \\
\hline$A D 10$ & $+(E, W)$ & $-(E, W)$ & $-(E)$ & $-(E)$ & $-(E)$ \\
\hline
\end{tabular}

+, binding; -, no binding; n.t., not tested. 

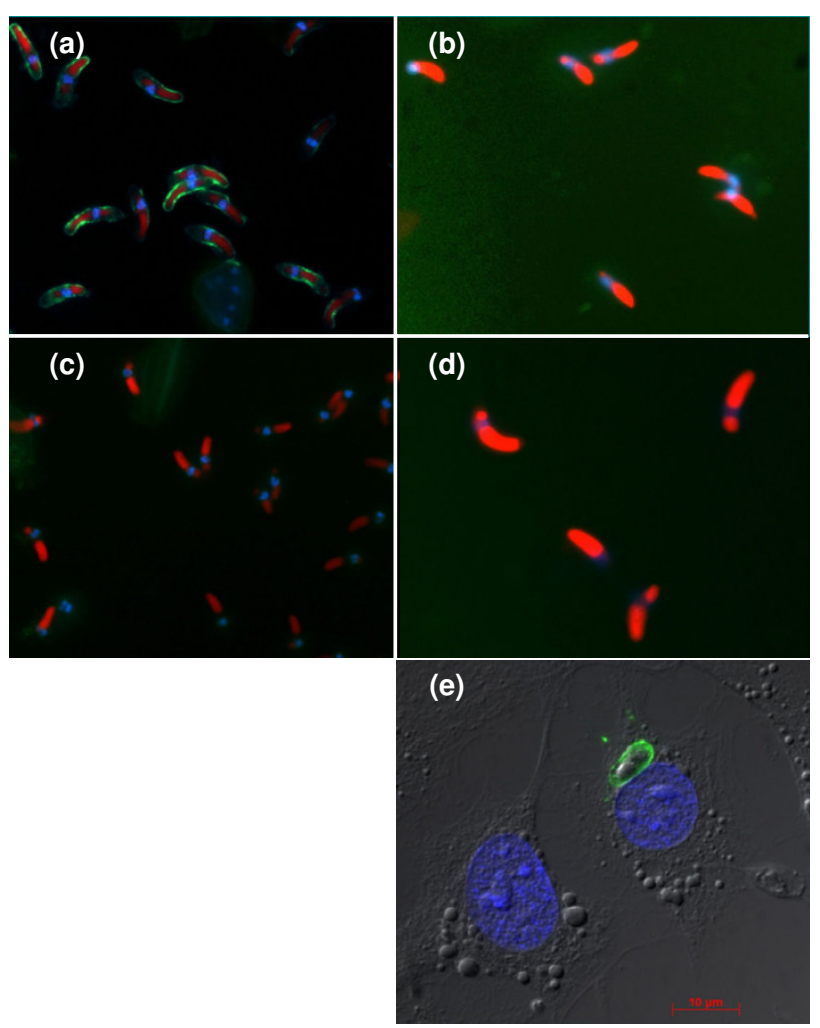

Figure 2

IFAT analysis demonstrating specific binding of scFv AB28 to sporozoites of E. tenella (a) and lack of interaction with sporozoites of $E$. acervulina (b) and $E$. brunetti (d). Negative control (binding of irrelevant scFv) is shown in panel (c). Blue fluorescence (DAPI), staining of nuclei; red fluorescence (Evans blue), staining of sporozoite refractile bodies and cytoplasm; green fluorescence (FITC), specific antibody staining. In panel (e), a fluorescence microscopy image is shown of intracellular sporozoite in infected HepG2 cell. Staining was performed with scFv AB28 followed by anti-c-myc MAb and Alexa488-conjugated anti-mouse antibody.

strated fairly broad species cross-reactivity (Table 3; Figure $3 \mathrm{~b})$. However, these variants neither bound to sporozoite and merozoite extracts nor interacted with the surface of sporozoites (Table 2).

\section{Oral application of tobacco expressed antibody fragments} in chickens infected with Eimeria

Oral application of antibodies for prevention of Eimeria infections in poultry would only be feasible if cheap sources of large amounts of recombinant protein were available. Production in plants provides an economically attractive source of recombinant antibodies [19]. Therefore, the recombinant anti-Eimeria antibody fragments were first expressed in leaves of the tobacco plant Nicotiana benthamiana as a quick source of large amounts of plant-made recombinant protein. Typically, one-step purification yielded 20,100,90, 400 and $60 \mathrm{mg}$ of recombinant scFv variants AA28, AB09, AB21, AB28 and AD10, respectively, with purity above $90 \%$ from $1 \mathrm{~kg}$ wet weight of infiltrated tobacco leaves (Figure 4). Comparison of the anti-sporozoite activity in vitro of the antibody fragments isolated either from tobacco or from E. coli demonstrated superior properties of the plant-produced material for most of the tested anti-Eimeria scFvs (Figure 1d).

Animal studies were performed to assess whether the scFvmediated inhibition of sporozoite invasion observed in vitro also prevents or mitigates Eimeria infections in chickens upon oral delivery of the scFvs. For these experiments, we used purified antibody fragments produced and isolated from the tobacco leaves. The chickens were orally infected with a single dose of E. tenella oocysts (500 oocysts per bird). One day before infection, force-feeding was started with the scFv fragments and continued for 9 days. Birds in the treatment group received $1 \mathrm{mg}$ antibody isolated from the tobacco leaves in $1 \mathrm{ml}$ PBS a day via gavage. The results of two independent animal trials performed in the same way are summarized in Figure 5. The untreated control groups showed oocyst shedding starting on day 6 after challenge and increasing throughout day 7 . At the same time points, treatment with the commercial anti-coccidian drug Baycox ${ }^{\circledast}$ reduced oocyst shedding to marginal levels. Animals that received scFvs experienced a partial (35-60\%) reduction in oocyst numbers in comparison with the untreated controls; however, there was no significant difference. The individual data sets of scFv-fed groups showed a fairly high variability between the experiments. Nevertheless, all tested scFv variants demonstrated a somewhat positive effect on oocyst shedding with the highest inhibition rate of $60 \%$ observed for the group treated with a scFv AD10.

\section{Pea plant transformation and expression of scFvs in pea seeds}

Although the transient expression of heterologous proteins in leaves of $N$. benthamiana allows relatively quick production of reasonable quantities of the scFv fragments for proof-of-concept (POC) animal studies, application of antibodies as fodder additives in routine poultry feeding requires more efficient and cost-effective production systems. Therefore, stable expression of single-chain antibody fragments was established in the fodder pea variety "Eiffel". For generation of the transgenic pea lines, the genes of scFv fragments of two different specificities (antiEtSAG1 scFv AB28 specific for E. tenella and scFv AA28 with the broadest cross-reactivity to Eimeria species) were selected. The transgenic pea lines have been generated which express scFvs under the control of a seed-specific promoter. The results of characterization of AB28-expressing pea lines are summarized in Additional files 1, 2, 3 \&4. 
(a)

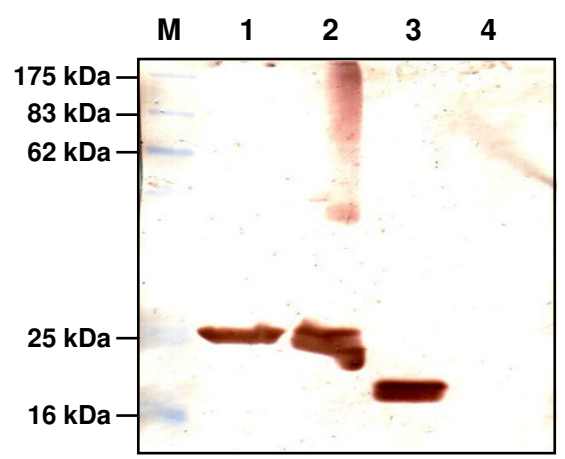

(b)

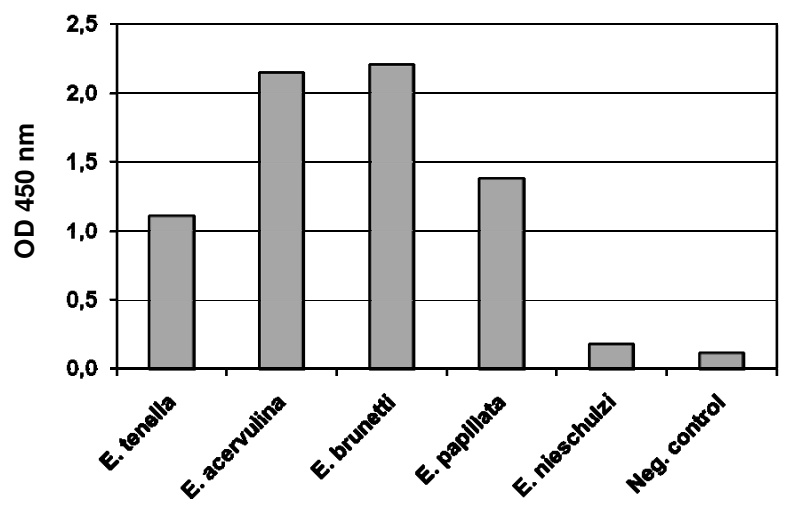

Figure 3

Analyses of specificity of sporozoite-neutralizing scFvs. (a) Western blot analysis of antigen specificity of scFv $A B 28$. Lanes: $M$, molecular mass markers (values in $\mathrm{kDa}$ are shown on the left); I,2, produced in $E$. coli $25 \mathrm{kDa}$ precursor of a GPI-anchored surface antigen EtSAGI under reducing and non-reducing conditions, respectively; 3,4, oocyst extract of $E$. tenella under non-reducing and reducing conditions, respectively. (b) Species specificity of scFv AA28, as determined by ELISA using oocyst extracts from three avian (E. tenella, E. acervulina, E. brunetti) and two rodent (E. papillata and $E$. nieschulzi) Eimeria species. As a negative control, secondary anti-c-myc tag antibody followed by HRP-conjugated goat anti-mouse $\lg G$ antibody was used.

Similar analyses were performed for the AA28-transgenic pea lines. The tests demonstrated that scFv expression was restricted to seeds, where the scFv protein could unambiguously be detected by Western blot analysis (Additional file 1). For estimation of the expression levels, the scFv antibody fragments were isolated from the pea seeds and purified. Three independent measurements yielded $1.76 \pm$ $0.41 \mathrm{mg}$ extractable functional scFv AB28 per $1 \mathrm{~g}$ dry seed weight. Furthermore, the scFv expression levels stayed the same over a number of following homozygous pea generations $(1.66,1.92,1.64$ and $1.90 \mathrm{mg} s c F v$ per $1 \mathrm{~g}$ dry seeds of generations F4, F5, F6 and F7, respectively). Head-tohead comparison of $\mathrm{scFv} \mathrm{AB} 28$ preparations isolated either from the tobacco leaves $(\mathrm{n}=5)$ or from the pea seeds $(\mathrm{n}=3)$ demonstrated nearly identical molecular form compositions in different preparations. The scFv material from both tobacco leaves and pea seeds was mostly monomeric $(73.10 \pm 6.27 \%$ and $76.65 \pm 13.22 \%$ for the tobacco and pea material, respectively) with presence of a dimeric (diabody [20]) fraction $(25.68 \pm 6.08 \%$ and $20.80 \pm 9.62 \%$, for the tobacco and pea material, respectively) and some minor quantities of higher molecular forms, most probably tetramers $(1.17 \pm 0.44 \%$ and $2.5 \pm 0.35 \%$, for the tobacco and pea material, respectively) (Figure $4 \mathrm{~d}$ and Additional file 5). Accordingly, the scFv preparations from the tobacco leaves and pea seeds demonstrated very close similarity $(P=0.192)$ in their antigen-binding activities, with the calculated $K_{D}$ values of $3.53 \pm 1.24 \mathrm{nM}(\mathrm{n}=3)$ and $2.60 \pm 0.73 \mathrm{nM}(\mathrm{n}=5)$, respectively, as determined by ELISA (Additional file 5).

\section{Analysis of the proteolytic and $\mathrm{pH}$ stability in vitro}

For an effective prevention of parasite invasion into the intestinal epithelium of chickens, the antibody fragments must survive the harsh conditions of the GI tract, in particular, high protease content and acidic $\mathrm{pH}$, for a longer time. It is known that avians possess the same basic structures for nutrient extraction as other vertebrates but also exhibit specific features within their GI tract. These include a crop for storage of feed, a proventriculus (simple stomach), a gizzard and paired caeca. The $\mathrm{pH}$ values of specific sections of the chicken GI tract are the following: crop 4.5, proventriculus 4.4, gizzard 2.6, duodenum 5.7 to 6.0 , jejunum 5.8 , ileum 6.3 , colon 6.3 , caeca 5.7 , and bile 5.9 [21]. We, therefore, performed comparative analyses of influence of the expression system on the $\mathrm{pH}$ and proteolytic stability of the antibody fragments using as an example the EtSAG1-specific scFv AB28. First, we tested the influence of different $\mathrm{pH}$ conditions separately on formation of the antibody-antigen complexes ("binding") as well as on dissociation of already preformed antigen-antibody contacts ("dissociation"). The purified scFv AB28 preparations isolated either from tobacco leaves or from the transgenic pea seeds were compared. In addition, crude protein extract prepared from AB28-expressing pea seeds was included into the assay. The results presented in Figure $6 \mathrm{a}, \mathrm{b}$ demonstrate a fairly comparable effect of $\mathrm{pH}$ on all three antibody preparations. As expected from the general considerations, the marginal $\mathrm{pH}$ values had a more pronounced negative effect on the formation of the antigen-antibody complexes than on dissociation of the already bound antibody. In general, the found $\mathrm{pH}$ effect on formation and dissociation of the antibody $(\mathrm{Ab}) / \mathrm{anti}$ gen $(\mathrm{Ag})$ complexes rather reflects the stability of the $\mathrm{Ab} /$ Ag interface partly formed by the electrostatic interactions and hydrogen bonds between the charged and polar amino acid side chains than the folding/unfolding stability of the antibody molecules themselves. In conclusion, 
all tested $\mathrm{scFv} \mathrm{AB} 28$ preparations retained $70-100 \%$ of their maximal antigen-binding activity under the $\mathrm{pH}$ conditions prevalent in the caeca where the E. tenella sporozoite invasion takes place [22].

To simulate the protease-rich conditions of the small intestine, activity and stability of different scFv AB28 preparations were tested in presence of enteric proteases present in the intestinal fluid (chyme) isolated from the small intestine of chickens. Comparison of purified $\mathrm{scFv}$ AB28 preparations isolated either from the tobacco leaves or from the pea seeds demonstrated a three-fold higher resistance of pea-expressed material against proteolytic degradation in the small intestine (Figure 6c; Table 4). The scFv material present in crude pea seed extract appeared even more stable, 40 -fold more resistant than $\mathrm{scFv}$ purified from pea seeds and 100 -fold more stable than scFv from tobacco. This finding indicates a protective anti-protease effect of the pea seed content. To analyze whether this protective effect is seed-specific or just caused by the high protein content of the pea flour, we compared proteolytic stability of the tobacco-produced $\mathrm{scFv} \mathrm{AB} 28$ in the presence of either wild-type (wt) pea seed extract or irrelevant protein, such as bovine serum albumin (BSA). The final BSA concentration was $15 \%(\mathrm{w} / \mathrm{v})$, as adjusted according to the measured protein content of the pea seed extract. The results presented in Figure 6d and Table 4 indicate that presence of excess of irrelevant protein had no effect on scFv degradation in chicken intestinal fluid and that the stabilizing effect could be attributed exclusively to the content of the pea seed extract (45-fold gain in stability). The tobacco-made scFv AB28 premixed with the wt pea seed extract proved nearly as stable as an extract prepared from the AB28-expressing transgenic pea seeds (Figure 6d).

\section{Reduction of parasite shedding upon force-feeding of chickens with pea seed flour prepared from scFv- expressing seeds}

To test whether pea seeds expressing protective scFvs can avert infection with $E$. tenella, the flour prepared from the AB28-expressing seeds was used for treatment of chickens infected with E. tenella oocysts. For comparison, expressed in tobacco and purified scFv AB28 and an irrelevant scFv BA11 raised against enterotoxigenic Escherichia coli (ETEC) as well as BA11-containing pea seed flour were used. The study was designed to mimic the normal housing conditions, such as keeping birds in clean stables where only a few oocysts could be present which survived the disinfection procedure. A preliminary dose finding study demonstrated that infection with a dose as low as 7 15 oocysts per chicken results in measurable oocyst shedding. In addition, lowering the infection dosages led to a significant reduction of deviation between the individual animals. Therefore, the animals were infected with manu- ally prepared individual doses of $20 \pm 1$ oocysts. The chickens were force-fed three times daily either with $1 \mathrm{mg}$ in total of scFvs purified from the tobacco leaves or with the flour prepared from the scFv-expressing pea seeds. In latter case, the maximal delivered dose of functional $\mathrm{scFv}$ was estimated to be $0.5 \mathrm{mg}$ per bird a day (see Methods).

The results of the study are shown in Figure 7a. The average oocyst shedding was 1.5-fold lower in birds treated with the expressed in tobacco and purified $\mathrm{scFv}$ against Eimeria (AB28) in comparison to birds that were treated with the same amount of a purified irrelevant scFv (BA11), although the difference was not significant $(P=$ $0.116)$. However, treatment with AB28-containing pea seed flour resulted in a significant 2.5 -fold lower average oocyst shedding than in the animal group receiving BA11 pea flour $(P=0.033)$. For groups treated with the pea material, the anti-Eimeria scFv antibody AB28 showed an infection inhibition of $60.5 \%$. For groups treated with the purified material, essentially lower inhibition (34.7\%) was observed.

\section{Mitigation of Eimeria tenella infection by application of scFv-containing pea seeds in chicken feed}

For demonstration of the potential of fodder containing AB28-pea shred in prevention or mitigation of the coccidian infection caused by E. tenella, the controlled battery experiments were performed under normal ad libitum feeding conditions. To determine whether the transgenic pea shred is accepted as a part of the feed and readily taken up by chickens as well as to assess the digestibility of the pea shred, a preliminary feeding study was performed using a fodder containing $10 \%$ pea shred derived from the pea seeds expressing irrelevant anti-ETEC scFv antibody BA11. The results shown in Additional file 6 demonstrated no difference in weight gain and feed consumption between the BA11-fed chickens and the animals of the control group. The transgenic pea shred was well consumed by broiler chickens and was not shunned (Additional file 6). ELISA analyses demonstrated absence of the BA11-activity in extracts from the fecal material, thus indicating that the recombinant antibody present in transgenic pea seeds was completely digested (data not shown).

In our feasibility studies, we evaluated high- and low-dose infection models. The high dose model was designed to get appropriate lesion scores for differentiation of infections. However, taking into account that the lesion score analysis is not always a reliable method to measure the efficacy of anti-coccidials [23], the reduction of oocyst counts in caeca was determined as an endpoint of the study. Broiler chickens were infected orally with individual doses of 2,500 freshly prepared oocysts of E. tenella. Three animal cohorts were formed; in two groups birds 
(a)

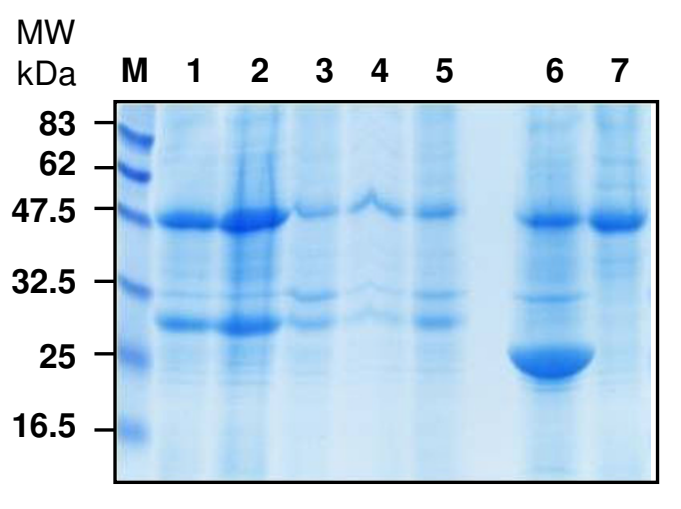

(b)

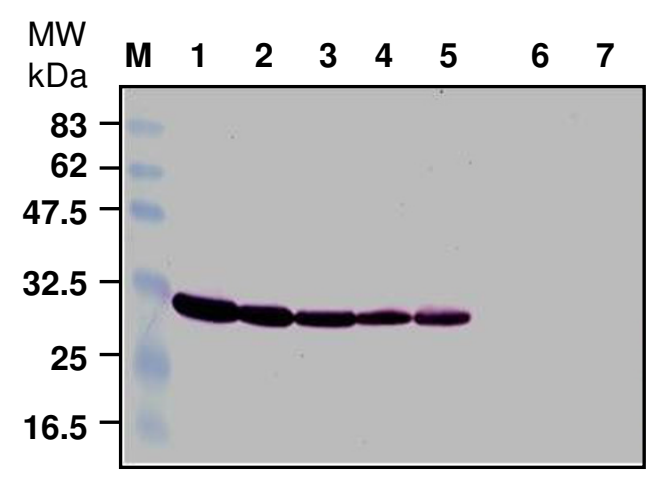

(c)

(d)

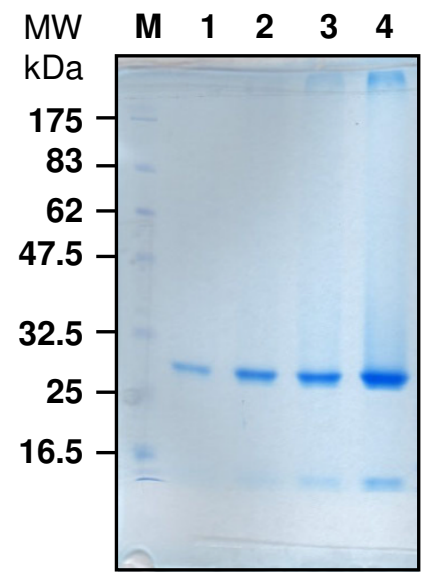

kDa $\quad 75 \quad 43 \quad 2913.7 \quad 6.5$

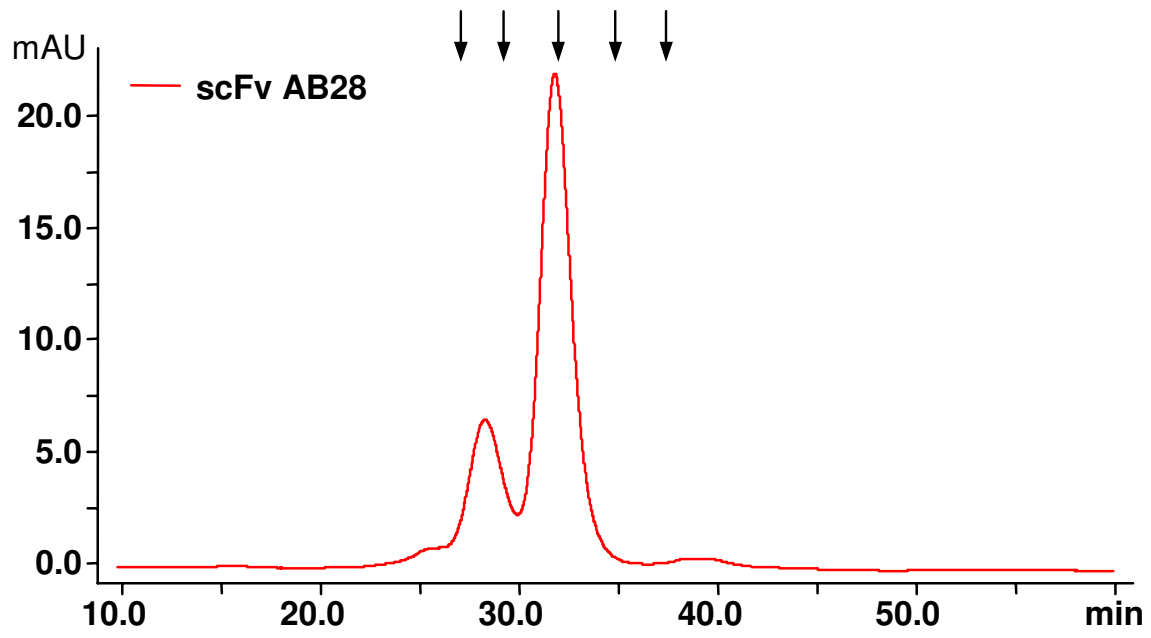

\section{Figure 4}

Analysis of scFv AB28 expression in tobacco leaves. (a, b) Reducing I2\% SDS-PAGE analysis of leaf discs: Coomassie staining (a) and Western blot with detection using anti-His antibody (b). Lanes: $M$, molecular mass markers (values in kDa are shown on the left); I-5, leaf materials after expression of scFv AB09, AB28, ADI0, AA28 and AB2 I, respectively; 6,7, negative controls (tobacco expressing GFP and wt plants, respectively). (c,d) Characterization of tobacco expressed scFv AB28 after purification. (c) Coomassie stained I2\% SDS-PAA gel. Lanes: M, molecular mass markers; I -4, scFv samples (I.3, 2.6, 5.2 and I $3 \mu \mathrm{g}$, respectively). (d) Analysis of scFv AB28 molecular forms by size-exclusion FPLC on a calibrated Superdex 200 column. The positions of the molecular weight markers are indicated.

were infected and fed with the fodder comprising $10 \%$ pea shred derived either from AB28-expressing seeds (treatment group) or from the wild-type pea (positive control of infection). Adapted from the preliminary feeding experiment, the average consumption of the scFv antibody by chickens of the treatment group was estimated as $35.63 \pm 1.87 \mathrm{mg}$ antibody $/ \mathrm{kg}$ body weight $\times$ day (Addi- tional file 7). The negative control group (control of spontaneous infection) comprised birds which were not infected and received conventional fodder. At the end of experiment, the lesion scores and the oocyst counts were determined in caeca of sacrificed birds. The results of the study demonstrated that there was no significant difference in the body weight gains $(P=0.068)$ and severity of 


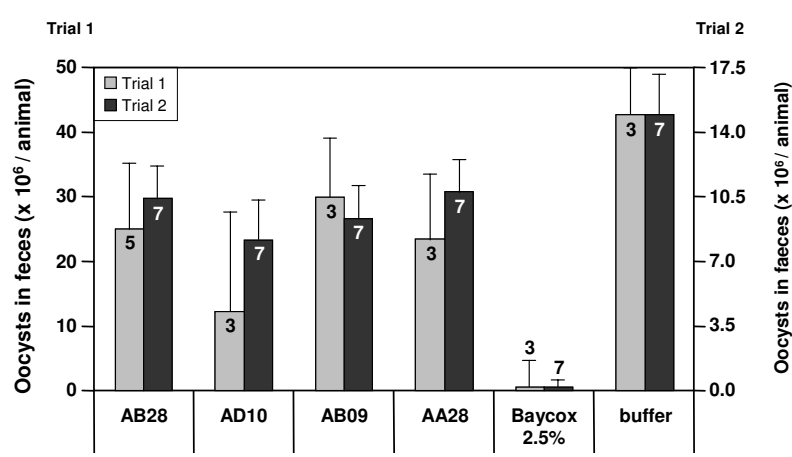

\section{Figure 5}

Evaluation of activity in vivo of orally applied antiEimeria antibodies. Infection outcomes were assessed by quantifying the amounts of Eimeria oocysts in feces of the infected chickens. Birds in the treatment groups received I $\mathrm{mg}$ antibody isolated from tobacco leaves in I $\mathrm{ml}$ PBS a day via gavage. The negative treatment group received buffer alone. Animals of the positive control group received $\mathrm{I} \mathrm{ml}$ of a $2.5 \%$ solution of the anti-coccidial drug Baycox ${ }^{\circledR}$ (Bayer HealthCare) in water. The results of two independent studies are presented. Mean values and SDs for each treatment group are plotted. The numbers of animals in each chicken cohort are indicated on the bars.

the lesions $(P=0.205)$ between the infected groups. However, less animals in the AB28-treated group had blood in feces ( $40 \%$ vs. $44 \%$ in the positive control group) and a higher proportion of the AB28-treated animals had lightweight lesions (50\% AB28-pea fed animals had lesion scores 0 and 1 vs. $40 \%$ in the positive control group). Accordingly, only $26 \%$ of the AB- 28 treated animal had lesion score 3 versus $36 \%$ in the positive control group. Although the mentioned differences were not statistically significant, the observed trend was confirmed when the oocyst counts from caeca were compared (Figure 7b). The average oocyst counts were significantly lower in birds fed with the AB28-expressing pea seeds than in animals receiving conventional fodder $(P=0.038)$. Feeding with $\mathrm{AB} 28$-pea led to reduction of the oocyst counts in caeca to $65.9 \%$ of the numbers found in the positive control group. Therefore, the inhibition of invasion caused by the AB28-transgenic fodder could be calculated as 34.1\%.

The low-dose infection model was employed to mimic the real situation in barns for rearing commercial broilers where the chickens are spontaneously infected with relatively low dosages of Eimeria oocysts. The feeding experiment was performed under nearly the same conditions as the high-dose infection experiment, only the infection dose has changed. In this study, the chickens were infected with the ten-fold lower oocyst doses, i.e. 250 oocysts per bird. Due to the low oocyst doses, the vast majority of infected chickens had reduced lesion scores 0 and 1
(100\% and $96 \%$ in AB28-treated and in positive control groups, respectively). The animal cohort fed with AB28pea seeds demonstrated significantly lower oocyst counts in caeca $(P=0.032)$. However, about one third of animals in both infected groups stayed oocyst-free most probably due to the innate immunity against the pathogen. Therefore, the effect of modified feed was also separately assessed only for the oocyst-shedders in each group. The results presented in Figure 7c demonstrate very significant reduction of caecal oocyst counts in the birds fed with the AB28-containing fodder $(P=0.002)$. In summary, feeding with AB28-pea seeds led to a reduction of the oocyst counts in caeca to a level of $29.2 \%$ from the counts found in the positive control group. Therefore, the inhibition of invasion caused by the scFv AB28 pea seed material could be calculated as $70.8 \%$.

\section{Discussion}

In view of the spread of microbial resistance to antibiotics and the emergence of new pathogens, passive immunization by recombinant antibodies is considered as one of the most promising alternatives to combat infectious diseases $[24,25]$. Although the market for therapeutic monoclonal antibody-based products is one of the fastest growing segments in the biopharmaceuticals industry, this market is heavily focused on oncology, autoimmune and inflammatory diseases. The role of antibodies for mitigation and therapy of infections is only slowly emerging, but is impeded by the high Cost of Goods (COG). High COG also prevents successful introduction of antibodies into the animal health market. Plant-based production provides a solution to these cost problems. In addition, plants can provide an adequate system for oral delivery of recombinant biomolecules as part of the diet. Infrastructure and costs for downstream processing can thus be avoided, as well as the production losses which are often significant. Although expression of recombinant antibodies and antibody fragments in plants ("plantibodies") has been demonstrated two decades ago [26], their introduction into the health and veterinary markets is still years away. In our knowledge, the present report is a first demonstration of feasibility to control poultry infections by feeding animals using a fodder supplemented with the antibody producing transgenic seeds.

The first objective of this study was generation of recombinant neutralizing antibodies against the economically important protozoan parasites of genus Eimeria. An immune library was constructed by phage display and panned against the complex antigens prepared from the different live forms of E. tenella. Since the orally delivered antibodies cannot rely on effector functions of circulating immunoglobulins such as Fc-receptor mediated recruitment of the immune killer cells (ADCC) or complement fixation (CDC) inside the GI tract, the only possible mechanism of action would be prevention of the parasite 
(a)

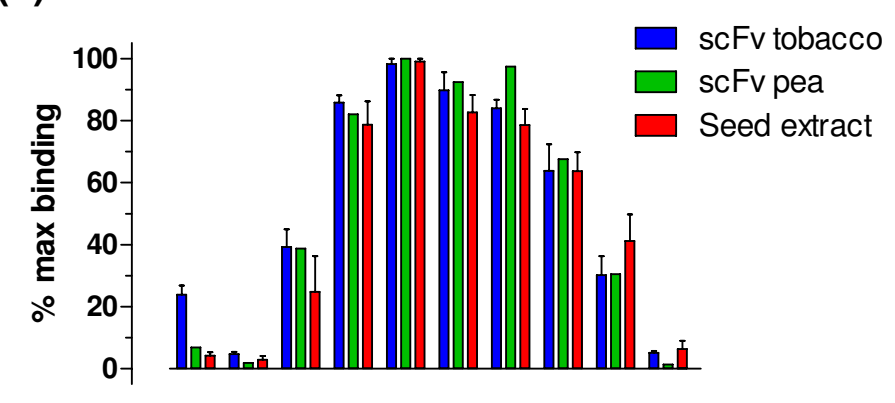

(c)

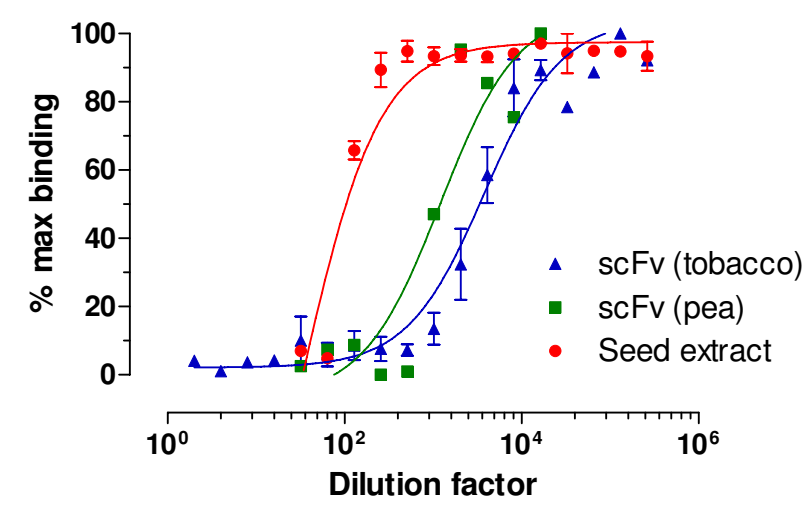

(b)
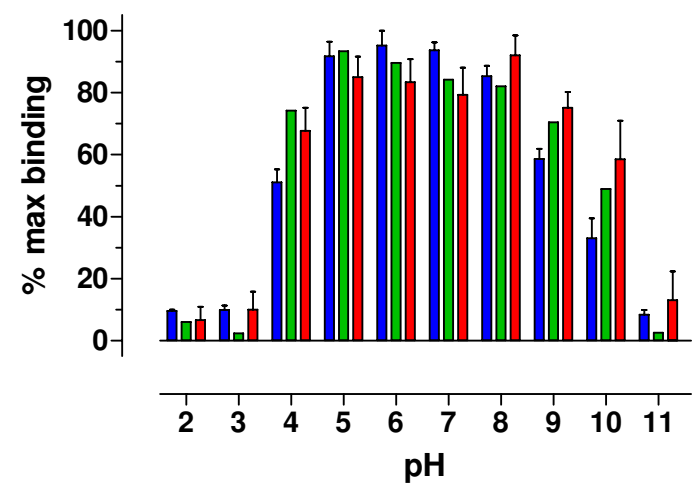

(d)

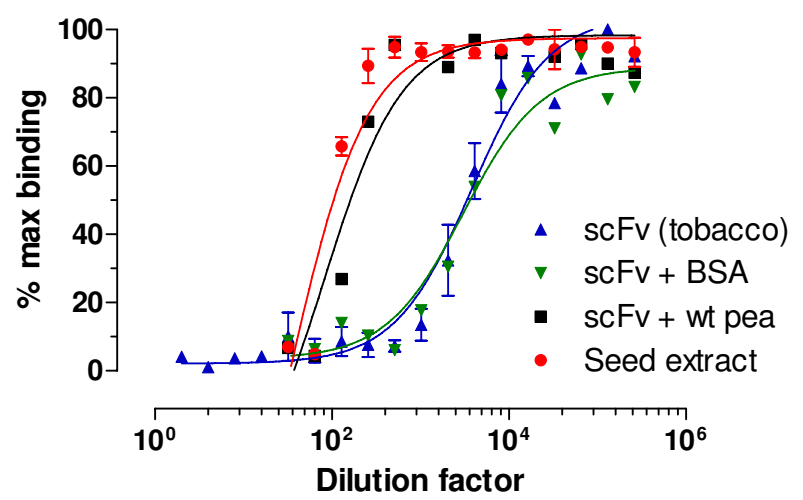

Figure 6

Analyses of pH and proteolytic stability of scFv AB28 preparations purified either from tobacco leaves or pea seeds and of the AB28-containing pea seed extract. (a, b) $\mathrm{pH}$ influence on formation ("binding") and disruption ("dissociation") of the antibody-antigen complexes formed by different AB28-preparations ( $\mathbf{a}$ and $\mathbf{b}$, respectively). (c, $\mathbf{d}$ ) Loss of antigen-binding activity of scFv AB28 preparations as a result of degradation by intestinal proteases. (c) Comparison of purified scFv AB28 isolated either from tobacco leaves or from pea seeds as well as of crude protein extract from the scFv-expressing seeds (seed extract). (d) Effect of irrelevant protein (BSA) or wt pea seed extract on proteolytic stability of scFv AB28 (tobacco) in chicken intestinal fluid. For comparison, a degradation curve for AB28-transgenic seed extract is shown. The residual antigen-binding activity was determined by ELISA using the plates coated with the oocyst extract of $E$. tenella and plotted against the chicken intestinal fluid dilutions.

entry into the gut epithelium. Therefore in contrast to the previously described approaches $[27,28]$, we introduced screening of binders for the parasite neutralizing activity early into the selection process. This strategy resulted in identification of six candidates; four of them appeared to be specific for EtSAG1 (TA4) sporozoite antigen of E. tenella. EtSAG1 has been found previously by us and others to be a molecular target for a number of sporozoite-neutralizing antibodies $[12,29,30]$ and seems to be closely involved into initiation of the infection process [30]. The antigen specificities of two neutralizing non-EtSAG1 binders and the mechanism of their infection-blocking activity are still unknown, since both these variants bound neither sporozoites nor merozoites.
The second goal of the study was testing the suitability of orally applied antibody molecules for controlling the Eimeria infection. To make the product compatible with the already existing cost structures in the animal health market, the cost efficient plant production systems have been utilized. First, the selected antibody fragments were transiently expressed in agrobacteria-infiltrated tobacco leaves and purified. Besides the higher production yields, the tobacco-derived antibody fragments demonstrated superior biological activity in vitro in comparison with the counterparts expressed and purified from bacteria. Furthermore, the relatively small quantities of tobacco-made $\mathrm{scFv}$ fragments ( $1 \mathrm{mg}$ per chicken a day, 8 day treatment) 
Table 4: Effect of expression system and additives on proteolytic stability of scFv AB28.

\begin{tabular}{ll}
\hline scFv preparation & $E D_{50}$ \\
\hline scFv (tobacco) & $3,786.00$ \\
\hline scFv (pea) & $1,209.00$ \\
\hline scFv (tobacco) $+15 \%$ BSA & $3,053.00$ \\
\hline scFv (tobacco) + wt pea seed extract & 83.24 \\
\hline$A B 28$-pea seed extract & 33.47 \\
\hline
\end{tabular}

$E D_{50}$, effective dilution of chicken intestinal fluid leading to $50 \%$ loss of activity.

were able to cause partial reduction of Eimeria oocyst shedding by the infected animals.

Although the transient and stable expression in tobacco leaves allows the cost-reasonable industry-scale production of heterologous proteins [31,32], it requires fairly intense product purification strategies, to remove at least the toxic alkaloids from the tobacco extracts. In contrast, expression of the therapeutic proteins in crop seeds has a great advantage for oral administration since only minimal treatment is necessary to use seeds as the livestock fodder. The other advantages of crop plants include easy upscaling through field cultivation, established harvesting and processing technologies, as well as easy seed storage and distribution. Seeds are natural storage organs, with the optimal biochemical environment for the accumulation of large protein amounts. In this form, proteins can be transported from farm to the production factories without any loss of stability. Moreover, feasibility of high-level production and long-term storage of antibodies in seeds has already been demonstrated [33,34]. In our work, we have selected feed pea as a production plant on the basis of the following considerations. Pea is an established field crop with available infrastructure and tools for large scale planting, weeding, harvesting, storage and processing. Furthermore, the pea seeds are an established feed/food ingredient with high protein content (up to 40\% [35]). Pea has a history of successful heterologous expression studies including field trials (own unpublished data) and has excellent safety features. The safety aspects include strict self-pollination; lack of outcrossing; no dispersal of seeds by wind and, therefore, very low number of volunteers; lack of toxic substances in seeds. The eaten seeds get digested and thus are not able to germinate; the pea plants do not survive frost. In addition, the pea varieties are approved as crop plants for livestock fodder. Due to the different sugar and glycopeptides contents, the feed pea has different taste and texture than the food pea, thus allowing easy discrimination to prevent potential entering of GMO into the food chain. In addition, using seed-spe- cific promoter makes expression of the transgenic protein nearly totally restricted to the seeds [36]. The safety features are very important in view of tight regulatory control and surveillance of genetically modified (GM) plants [37].

We have, therefore, generated transgenic pea plants expressing two most promising scFv candidates in seeds. The highest producer, a homozygous pea line expressing anti-EtSAG1 scFv AB28 at yields of 1.5-2 g extractable functional antibody per $1 \mathrm{~kg}$ dry seeds, was taken for the detailed analyses and feasibility studies in animals. Comparison of the $\mathrm{scFv}$ fragments isolated from the pea seeds with the counterparts expressed in tobacco leaves (a plant expression system most often used for production of antibodies and their fragments $[31,34]$ ) demonstrated no difference in the molecular form composition, antigen binding activity and $\mathrm{pH}$ stability, but a somewhat higher resistance of the pea seed derived material against intestinal proteases. Comparative analysis of the proteolytic resistance revealed a key protective role of the pea seed extract in scFv stability. The stabilizing effect can be attributed to the well-known presence of the proteinase inhibitors in legume seeds [38]. The trypsin/chymotrypsin inhibitors found in pea seeds mainly belong to the Bowman-Birk protease inhibitor (BBI) family. BBIs are stable at cooking temperatures and also towards acidic $\mathrm{pH}$ values in the digestive systems of humans and animals, most probably due to their large number of disulfide bonds (seven bonds out of about 70 amino acid residues) and the polar interactions between the sub-domains. The potential applications of BBIs have recently attracted much attention. BBIs are already used to defend against insects in transgenic plants, and they also have prospects in the prevention of cancer, Dengue fever, and inflammatory and allergic disorders (for review see $[39,40]$ ). These findings provide an additional argument for choosing the legume seeds as the production system suitable for passive immunization.

The controlled feeding experiments demonstrated statistically significant positive effect of using antibody-expressing transgenic pea seeds on mitigation of coccidial infection. In first instance, force-feeding with the pea flour suspension appeared to be more efficient than the oral administration of twice larger amounts of purified antibody fragments. The found effect was additionally confirmed by ad libitum feeding using both high- and lowdose infection models. The challenge doses of E. tenella oocysts that were used in the first model $\left(2.5 \times 10^{3}\right)$ may be considerably greater than the levels that commercial birds are likely to be exposed to in some production facilities. Nevertheless, the observed endpoint of the study (reduction of oocyst counts is caeca) was still significant. Much better results were obtained by using the ten-fold lower challenge oocyst doses. Therefore, the transgenic pea seeds may be useful for protection against coccidiosis 
(a)

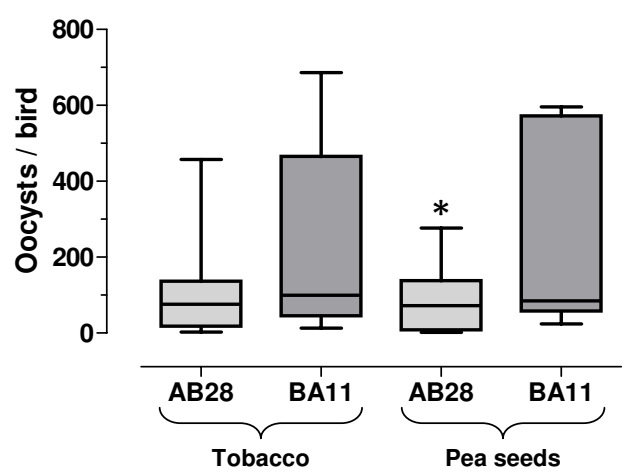

(b)

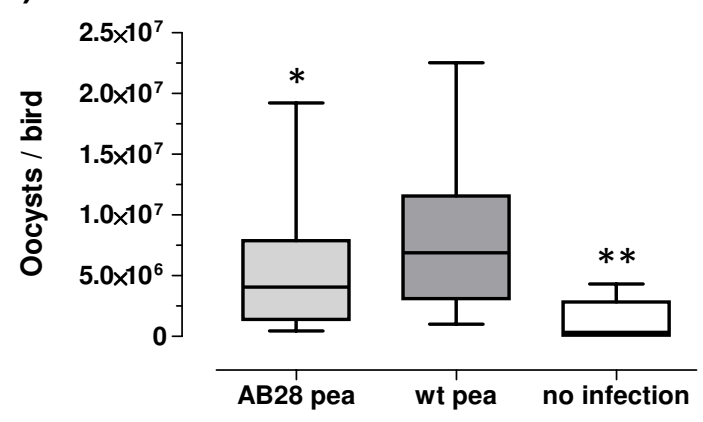

(c)

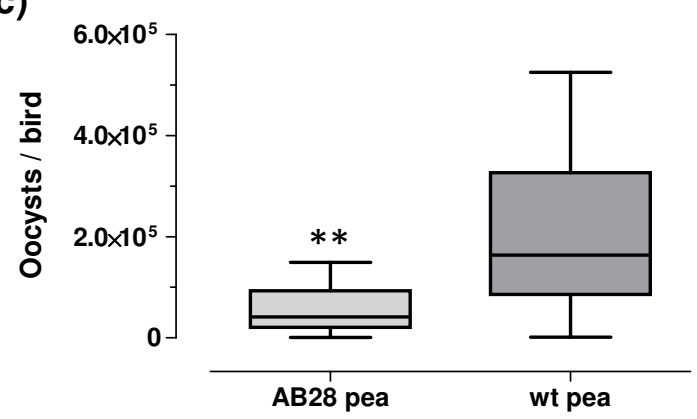

\section{Figure 7}

Evaluation of anti-Eimeria activity in vivo of fodder containing antibody-expressing pea seed flour or shred. (a) Analysis of activity in vivo of orally applied antibody-containing pea seed flour (force-feeding). The animals were infected with manually prepared individual doses of $20 \pm I$ oocysts. Two evaluation groups $(n=I I)$ were treated with the material containing anti-Eimeria scFv AB28, one group received pea flour from seeds expressing AB28 and the other group was treated with the antibody fragment isolated from the tobacco leaves. As positive controls of infection, two animal groups (II birds in each) were treated with the same quantities of material comprising the irrelevant BAII antibody, either in form of pea flour or as soluble antibody isolated from the tobacco leaves. The negative control group comprised five birds to who heat inactivated oocysts were given. The oocyst counts were determined in individual feces and each sample was counted six times by two different persons. The infection outcomes were assessed by quantifying the amount of Eimeria oocysts in feces of infected chickens at days 7 and 8 p.i. (days of maximal oocyst release). (b) High infection dose model (ad libitum feeding). Three treatment cohorts were evaluated: group I $(n=30)$ received fodder with 10\% AB28-pea shred; group $2(n=25)$, positive control for infection (infected, not treated); group $3(n=5)$, negative control of infection (non-infected, not treated). The birds in groups 2 and 3 were fed with the fodder containing 10\% wt pea. Infection outcomes were assessed by quantifying the amounts of the Eimeria oocysts in caeca of infected chickens at day 7 p.i. (c) Low infection dose model (ad libitum feeding). Infection outcomes were assessed by quantifying the amounts of the Eimeria oocysts in caeca of infected chickens at day 7 p.i. Due to the relatively low infection rate, only the oocyst shedding animals were considered, i.e. I7 birds from the group I (AB28) and I3 animals from the group 2 . 
in poultry raised under normal field conditions, as we demonstrated using the low-dose infection model.

Although the results presented here are rather preliminary, they provide evidence that the recombinant antibodies produced in pea seeds have capacity to reduce the infectious loads in animals following oral administration. Product-specific issues such as antibody stability in the gut, parasite neutralizing potency or even direct killing activity have to be addressed, as well as technical issues (increasing the production yields and shortening time for GM plant generation) and commercial applicability. For example, in the present study we used the scFv variants selected from the phage display immune library without any further optimization. Affinity maturation of the $\mathrm{scFv}$ candidates and improving their proteolytic stability and folding efficacy in plants using either random or rational approaches [41] may further contribute to the success of the described passive vaccination strategy. The antibody stability against intestinal proteases can also be enhanced by conversion of $s c F v$ into a bivalent single-chain antibody format without compromising the expression yields in plants that is normally observed for heterooligomeric full-length antibodies of IgG and IgA classes or Fab fragments (Giersberg et al., manuscript in preparation). Alternatively, well expressed and proteolytically stable binding proteins selected from the non-antibody scaffold libraries can be used (for review see [42]). In addition, further enhancement of anti-parasite potency can be achieved, for example, by grafting the killing antimicrobial peptides into the antibody CDR loops not involved into the antigen binding [43].

\section{Conclusion}

Taken together, this study demonstrated for the first time beneficial effect of using antibody expressing pea seeds for passive protection against avian coccidiosis in newly hatched birds. Compared with methods of active vaccination either by live parasites (wild-type and/or attenuated strains) or using recombinant subunit or DNA vaccines [1], the passive immunization strategy described here is an easy and non-invasive method to use in commercial settings with the comparatively low cost of production utilizing current agriculture technologies and with the ability to be used in combination with other anti-parasitic agents.

\section{Methods}

Immunization of mice and generation of a phage display antibody library

For library generation, six BALB/c mice were immunized by injecting $100 \mu \mathrm{l}$ of a mixture containing 1.0 to $3.9 \times 10^{6}$ purified parasites (oocysts, sporocysts and sporozoites) of five Eimeria strains (E. tenella, E. acervulina, E. necatrix, E. maxima and E. brunetti). For immunization, the Eimeria oocysts were sporulated and used for isolation of viable sporozoites as described by Raether et al. [44]. The protein extracts from sporulated oocysts and sporozoites were prepared by vortexing the parasite stages with glass beads in PBS containing $1 \mathrm{mM}$ PMSF, followed by six freezethaw cycles for parasite disruption and sonication on ice. Soluble extracts were obtained by additional centrifugation for $10 \mathrm{~min}$ at $13,000 \mathrm{~g}$. Three immunizations were applied on day 1, day 21 and day 41, respectively. Successful immunization was monitored by performing IFAT tests with immobilized E. tenella sporozoites. RNA was isolated from spleens of the mice (RNAeasy Midi-Kit, Qiagen) and polyA+ RNA purified (Oligotex-mRNA-Mini-Kit, Qiagen). First strand cDNA was obtained using the SuperScript First-Strand Synthesis System for RT-PCR from Gibco BRL. PCR amplification of the $V_{H}$ and $V_{L}$ regions using minimal primers Bi3f/Bi4 for $\mathrm{V}_{\mathrm{H}}$ and $\mathrm{Bi} 5 \mathrm{C} / \mathrm{Bi} 8 \mathrm{~b}$ for $\mathrm{V}_{\mathrm{L}}[45]$ was used as quality-control for the cDNA. For the construction of the phage-display library, cDNA encoding the $\mathrm{V}_{\mathrm{H}}$ and $\mathrm{V}_{\mathrm{L}}$ domains was generated by PCR using a described mouse immunoglobulin primer set [46]. As a vector for phage surface display, a phagemid pEXHAM1 [47] was used which was derived from pSEX81 [48] by inserting a DNA sequence encoding a tag that consists of six histidine residues (His6-tag), an amber stop codon $(\mathrm{Am})$, and a c-myc epitope between the scFv and the M13 g3p gene. The amplified $\mathrm{V}_{\mathrm{H}}$ genes were cloned as NcoIHindIII fragments to substitute a $\mathrm{V}_{\mathrm{H}}$ gene of a dummy scFv containing a YOL-linker [49] in the PEXHAM1 vector. The ligated phagemids were used for transformation of $E$. coli XL1-Blue cells (Stratagene) to generate a $\mathrm{V}_{\mathrm{H}}$ sublibrary of $10^{7}$ individual clones. The produced DNA was used for cloning the $\mathrm{V}_{\mathrm{L}}$ gene repertoire as MluI-NotI DNA fragments. The overall achieved scFv library complexity was $5.5 \times 10^{7}$ individual clones.

\section{Screening of the phage-display library and selection of Eimeria-specific antibodies}

The antigen immobilization and library screening was performed according to published protocols $[45,46]$. For isolation of scFvs that bind to Eimeria proteins, soluble protein extracts of E. tenella oocysts, sporozoites and merozoites were used as complex antigens for panning of the scFv library. Merozoites were isolated from the intestinal scrapings according to Shirley [50]. The merozoite protein extracts were prepared as described above for the oocysts and sporozoites. The cell pellets resulting from preparation of soluble protein extracts of oocysts and sporozoites were used to extract the membrane proteins. Cell pellets were resuspended in extraction buffer $(0.1 \mathrm{M}$ Tris$\mathrm{HCl}, \mathrm{pH}$ 6.8, 5 mM EDTA, 1\% Triton X-100, 1 mM PMSF) and incubated at $4{ }^{\circ} \mathrm{C}$ overnight. The membrane protein fraction was separated by centrifugation for $20 \mathrm{~min}$ at $13,000 \mathrm{~g}$. For antigen immobilization, Nalge/Nuncmicrotiter plates were coated with $2 \mu \mathrm{g}$ Eimeria extracts in 
PBS overnight at $4{ }^{\circ} \mathrm{C}$. After blocking with $2 \%$ BSA/PBS, 5 $\times 10^{10} \mathrm{cfu}$ phages were added to the wells and incubated at room temperature for $2 \mathrm{~h}$. After repeated washing (16x with PBS $/ 0.1 \%$ Tween, $4 \times$ with PBS), the bound phages were eluted with $0.1 \mathrm{M}$ triethylamine, $\mathrm{pH} 12.3$. The eluate was immediately neutralized with $1 \mathrm{M}$ Tris- $\mathrm{HCl}, \mathrm{pH} 7.4$ and used for infection of E. coli XL1-Blue cells in $2 \mathrm{xYT}$ medium. The rescued phagemids were packaged into the phage particles by superinfection of the phagemid-containing bacteria with M13K07 helper phage in 2xYT, 2\% glucose, $100 \mu \mathrm{g} / \mathrm{ml}$ ampicillin followed by incubation in presence of kanamycin $(70 \mu \mathrm{g} / \mathrm{ml})$ at $30^{\circ} \mathrm{C}$ overnight. Phage particles were collected from the culture medium by precipitation with $1 / 5$ volume 20\% PEG 6000/2.5 M $\mathrm{NaCl}$ and used for the next round of panning. In the first round of panning, $5 \times 10^{10} \mathrm{scFv}$ phages were applied, after three rounds of panning, amplification, and re-panning, 112 clones expressing scFv were obtained that bound the oocyst extract, 64 clones which bound sporozoite protein, 39 clones that bound membrane proteins from oocysts and sporozoites and 67 clones that bound merozoite proteins.

\section{Bacterial expression, isolation and purification of scFvs}

The selected binders were initially produced in E. coli bacteria carrying the pEXHAM1 phagemids encoding the corresponding scFvs. Bacterial expression was performed essentially as described [45]. Bacteria were grown at $37^{\circ} \mathrm{C}$ in LB medium containing $10 \mathrm{mM}$ glucose and $100 \mu \mathrm{g} / \mathrm{ml}$ ampicillin until $\mathrm{OD}_{600}$ of 0.6. Expression of the recombinant protein was induced by adding IPTG to a final concentration $50 \mu \mathrm{M}$ followed by further incubation of bacteria at $30^{\circ} \mathrm{C}$ for $3 \mathrm{~h}$. For isolation of periplasmic extracts, the bacterial cells were harvested by centrifugation at $4^{\circ} \mathrm{C}$ and resuspended in $1 / 10$ initial volume of cold spheroplast buffer (20\% sucrose, $50 \mathrm{mM}$ Tris-HCl, 1 $\mathrm{mM}$ EDTA, $\mathrm{pH}$ 8.0). After incubation for $20 \mathrm{~min}$ on ice, the spheroplasts were separated by centrifugation at 6,200 $g$ at $4^{\circ} \mathrm{C}$ for $10 \mathrm{~min}$. The supernatant containing the periplasmic extract was collected and further cleared by additional centrifugation at $30,000 \mathrm{~g}$ at $4{ }^{\circ} \mathrm{C}$ for $30 \mathrm{~min}$. For analyses of activity in ELISA, the periplasmic extracts were thoroughly dialyzed against PBS (50 mM $\mathrm{KH}_{2} \mathrm{PO}_{4} /$ $\mathrm{K}_{2} \mathrm{HPO}_{4}, 150 \mathrm{mM} \mathrm{NaCl}, \mathrm{pH}$ 6.6). The antibody fragments were isolated from periplasmic extracts by immobilized metal affinity chromatography (IMAC) on Ni-NTA Hisbind resin (Novagen) according to the manufacturer's instructions. Eluted fractions were analyzed for presence of antibody fragments by SDS-PAGE followed by Coomassie staining and by Western blot analysis using either anti-His-tag or anti-c-myc antibodies for detection. Fractions containing the target protein were pooled and prepared for ion-exchange chromatography (IEC). The protein solutions were dialyzed against an appropriate low-salt loading buffer with a $\mathrm{pH}$ approximately $1 \mathrm{pH}$ - unit above or below the calculated isoelectric point $(\mathrm{p} I)$. The following loading buffers were used for IEC: $50 \mathrm{mM}$ imidazole-HCl, pH 6.4 or $\mathrm{pH} 7.0$, and $20 \mathrm{mM}$ Tris $\cdot \mathrm{HCl}$, $\mathrm{pH}$ 8.0, for cation-exchange chromatography on Mono $\mathrm{S}$ 5/50 GL column (GE Healthcare Bio-Sciences AB, Uppsala, Sweden) and for anion-exchange chromatography on Mono Q 5/50 GL column (GE Healthcare), respectively. Separation was carried out using Äkta FPLC (GE Healthcare) with a linear salt gradient $(0-1 \mathrm{M} \mathrm{NaCl})$ in the loading buffer. Elution fractions of $1 \mathrm{ml}$ were collected and analyzed by SDS-PAGE followed by Coomassie staining and by Western blot analysis, as mentioned above. Selected fractions were pooled and thoroughly dialyzed either against PBS for analysis of $\mathrm{scFv}$ activity in ELISA or against DMEM-light $\left(1.8 \mathrm{mM} \mathrm{CaCl}_{2} \times 2 \mathrm{H}_{2} \mathrm{O}, 5.4 \mathrm{mM} \mathrm{KCl}\right.$, $0.8 \mathrm{mM} \mathrm{MgSO}_{4} \times 7 \mathrm{H}_{2} \mathrm{O}, 110 \mathrm{mM} \mathrm{NaCl}, 44 \mathrm{mM} \mathrm{NaHCO}_{3}$ $1 \mathrm{mM} \mathrm{NaH}_{2} \mathrm{PO}_{4} \times 2 \mathrm{H}_{2} \mathrm{O}, \mathrm{pH} 7.4$ ) for the invasion inhibition assay. The protein concentrations of purified $\mathrm{scFv}$ preparations were determined according to Bradford [51] using the Bio-Rad Protein Assay (Bio-Rad Laboratories $\mathrm{GmbH}$, Munich, Germany). If the final protein concentration was below $1 \mathrm{mg} / \mathrm{ml}$, the preparation was further concentrated using Vivaspin-6 or -20 (5000 MW PES, Sartorius AG, Göttingen, Germany). The antigen-binding activity of $\mathrm{scFv}$ preparations was tested in ELISA using oocyst extracts and/or recombinant antigens. Milk powder was used as a negative control antigen. The scFv preparations were stabilized by adding $1 \%(\mathrm{w} / \mathrm{v})$ bovine serum albumin (BSA), chilled in liquid nitrogen and stored at $-80^{\circ} \mathrm{C}$.

\section{In vitro invasion inhibition assay}

The invasion inhibition assay is based on the observation that Eimeria sporozoites are able to invade cultured MDBK cells. The assays were performed essentially as previously described [11,52]. In brief, sporozoites from cryopreservation were thawed and washed or freshly isolated sporozoites of E. tenella were labeled in HBSS (Invitrogen) with $1 \mu \mathrm{M}$ 5,6-carboxy-succinimidyl-fluoresceine-ester (CFSE, Invitrogen) for 30-60 min and washed twice with DMEM medium supplemented with $2.5 \%$ FCS (Invitrogen $\mathrm{GmbH}$, Karlsruhe, Germany). The labeled sporozoites (30,000-100,000/well) were preincubated with different dilutions of purified $\mathrm{scFv}(0.5-100 \mu \mathrm{g} / \mathrm{ml})$ or with the buffer control for $60 \mathrm{~min}$ at RT and thereafter used for infection of MDBK cells. One day prior the infection, the wells of 48-well Multidishes (Nunc, Wiesbaden, Germany) were seeded with 50,000 MDBK cells in $400 \mu \mathrm{l}$ medium. The cells were allowed to grow for 24 hrs to 60 $80 \%$ confluence in DMEM, 10\% FCS. After incubation of antibody-coated sporozoites with the cells at $37^{\circ} \mathrm{C}$ for 4 $16 \mathrm{hrs}$, the MDBK cells were washed, detached with Accutase (PAA Laboratories) and analyzed by flow cytometry using a flow cytometer CyFlow SL (Partec GmbH, Münster, Germany). The fluorescent free sporozoites as 
well as labeled sporozoites in infected cells were detected at $530 \mathrm{~nm}$. The infected cells, non-infected cells and free sporozoites were gated using software FloMax (Partec) for subsequent counting of the infected and non-infected cells. The deduced percentages of infected cells in presence/absence of inhibitory antibody were used for calculation of the inhibition rates as follows:

$$
=100 \times\left(1-\left[\% \text { infected cells }{ }^{\mathrm{scFv}} / \% \text { infected cells }{ }^{\text {neg. control }}\right]\right) .
$$

\section{Generation of recombinant Eimeria antigens}

As a source of genetic material, an E. tenella sporozoite specific cDNA library ( $\lambda$ ZAP II) [53] was used which was kindly provided by Dr. Marie Labbe (Laboratoire de Virologie et Immunologie Moléculaires INRA F 78352, Jouyen-Josas, France). A gene encoding a $25 \mathrm{kDa}$ precursor of a GPI-anchored surface antigen (EtSAG1; original name TA4 antigen; EMBL accession AJ586531.2) of E. tenella sporozoites [12] devoid of the signal and GPI-anchor sequences was amplified by PCR using a forward (sense) primer, 5'-ATG GTA GGT CTC AGG CCA TGC AGG ATT ACC CAA CAG CAG T, and a reverse (anti-sense) primer, 5'-ATG GTA GGT CTC AGC GCT GAC TGG AGA AAC TCC GCC CTT C, and cloned into BsaI-digested pASK-IBA2 expression vector (IBA, Göttingen, Germany). In the generated plasmid, the EtSAG1 gene was placed under the transcriptional control of the tetracycline promoter/operator and was preceded by the OmpA signal sequence for secretion of the recombinant protein into the bacterial periplasm. In addition, the expression product contained a C-terminal Strep-Tactin affinity tag (Strep-tag II) for purification. Protein expression was induced in E. coli shaking culture by adding anhydrotetracycline to a final concentration of $200 \mu \mathrm{g} / \mathrm{l}$. Affinity purification of the recombinant EtSAG1 antigen was performed according to the manufacturer's instruction. Alternatively, PelB leaderdriven periplasmic expression of the $25 \mathrm{kDa}$ EtSAG1 precursor with the C-terminal $\mathrm{His}_{6}$-tag was achieved using the bacterial expression vector pSKK3 [54] kindly provided by Affimed Therapeutics AG (Heidelberg, Germany). For cloning, the EtSAG1 gene was re-amplified from the previously described pASK-IBA2-based construct using the primers SAG-NcoI, 5'-ATA TTT CCA TGG CGG ATT ACC CAA CAG CAG, and SAG-NotI, 5'-ATG GGA TCC AGC GGC CGC GAC TGG AGA AAC TCC G, and cloned into NcoI/NotI-digested pSKK3. Bacterial expression in E. coli RV308, preparation of periplasmic extracts and antigen isolation by IMAC were performed essentially as described [55]. Fine purification of the IMAC-enriched recombinant EtSAG1 antigen (90-95\% purity) was achieved by anion-exchange chromatography on a Mono Q 5/50 GL column (GE Healthcare) in $20 \mathrm{mM}$ Tris- $\mathrm{HCl}$, $\mathrm{pH}$ 8.0, with a 0-1 M NaCl linear gradient. Elution fractions of $1 \mathrm{ml}$ were collected and analyzed by SDS-PAGE followed by Coomassie staining. The fractions containing most pure target protein were pooled and thoroughly dialyzed against PBS, pH 6.6. The recombinant EtSAG1 antigen was isolated with a yield of $5 \mathrm{mg} / \mathrm{l}$ bacterial culture and purity above $90 \%$. The other seven recombinant antigens of E. tenella used for analyses of specificity of the library-derived antibody fragments are listed in Additional file 8 . The corresponding genes were retrieved by PCR using the designed gene-specific primers and cloned into different bacterial expression vectors (Additional file $8)$. After sequence verification, expression in bacteria was performed according to the standard protocols [56] or to manuals of the corresponding vector manufacturer (Novagen/Calbiochem-Novabiochem GmbH, Schwalbach, Germany; IBA Göttingen GmbH, Göttingen, Germany). Depending on the vector system, the recombinant antigens were purified either by IMAC or by Strep-Tactin affinity chromatography.

\section{Analysis of binding properties and antigen specificity of selected scFvs}

ELISA and Western blot analyses were performed according to the standard protocols using oocyst extracts and recombinant antigens. For IFAT and flow cytometry, sporozoite isolation was performed from freshly passaged sporulated oocysts. After excystation, the sporozoites were purified by Percoll density gradient centrifugation [57]. Cryopreservation of sporozoites was carried out as described [58]. After thawing and washing, the sample was inspected by light microscopy for the correct number of parasites. For IFAT, isolated sporozoites of E. tenella were air dried in Lab-Tek ${ }^{\mathrm{TM}}$ Chamber Slides ${ }^{\mathrm{TM}}$ (Nunc, 178599). For fluorescent staining of intracellular sporozoites, HepG2 cells [59] were grown in Lab-Tek ${ }^{\mathrm{TM}}$ II Chamber Slides ${ }^{\mathrm{TM}}$ (Nunc, 154534) overnight followed by infection with 30,000 sporozoites per chamber for at least 2 hrs. Sporozoites and HepG2 cells, respectively, were fixed and permeabilized by methanol treatment $(90 \mathrm{ml}$ methanol/10 ml $100 \mathrm{mM}$ MES, $1 \mathrm{mM}$ EGTA, $1 \mathrm{mM}$ $\mathrm{MgCl}_{2}, \mathrm{pH}$ 6.9) for $5 \mathrm{~min}$. After blocking for $1 \mathrm{~h}$ with $5 \%$ BSA-PBS, the slides were incubated with $\mathrm{scFv}$ preparations (5-20 $\mu \mathrm{g} / \mathrm{ml}$ in 5\% BSA-PBS, $0.05 \%$ Tween-20) for $1 \mathrm{~h}$ at RT. Bound antibody fragments were detected by the Alexa555 or -488-conjugated anti-Penta-His antibody (Qiagen) ( $1 / 100$ dilution in 5\% BSA-PBS, $0.05 \%$ Tween-20). After each antibody incubation, the slides were extensively washed twice with PBS containing 0.05\% Tween-20, and once with PBS. In addition, the nuclei of HepG2 cells were stained with DAPI (4',6-diamidin-2'-phenylindoldihydrochlorid; Invitrogen; $3 \mu \mathrm{l} 0.02 \%$ stock solution per $1 \mathrm{ml}$ PBS) for 15 min during the final washing procedure. After removal from the chambers, the glass slides were mounted with Aqua-Poly/Mount, water-soluble non-fluorescing mounting medium (Polysciences Europe $\mathrm{GmbH}$, Eppelheim, Germany). The specimens were examined either by phase contrast light microscopy or by fluores- 
cence microscopy with blue light (470-490 nm) using an Axioplan 2 imaging mot and the AxioCam MR (Carl Zeiss Jena GmbH, Jena, Germany). For flow cytometry, 50,000100,000 sporozoites in each sample were incubated with the scFv-containing crude periplasmic extracts in dilutions $1 / 5-1 / 10$ in $500 \mu \mathrm{l}$ DMEM $+2.5 \%$ FCS for $1 \mathrm{~h}$ at RT. The sporozoites were washed once with $1 \mathrm{ml}$ PBS, collected by centrifugation at 2,500 $\mathrm{g}$ for $5 \mathrm{~min}$ and the scFvs were detected by an Alexa-488-conjugated anti-Penta-His antibody (Qiagen) (1/100 dilution in DMEM + 2.5\% FCS). After incubation for $1 \mathrm{~h}$ on ice, the relative fluorescence intensities were determined using a FACScounter (Partec).

\section{Transient expression of antibody fragments in tobacco leaves}

The system for transient expression in tobacco was based on MagnICON ${ }^{\mathrm{TM}}$ vectors from Icon Genetics $\mathrm{GmbH}$ (Halle, Germany) [60,61]. For transient expression in Nicotiana benthamiana, a modified version of the vector pICH10990 [60] was used. A DNA sequence encoding the poly-histidine tag was assembled from oligonucleotides 10990HIS1, 5'-CTG TAT ATC TGG ATC CCA TCA CCA CCA TCA CCA TTA G, and 10990HIS2, 5'-AGC TAA AGC AAG CTT ACT AAT GGT GAT GGT GGT GAT GGG ATC CAG, and cloned into the BamHI and HindIII sites of pICH10990, thus resulting in an intermediate plasmid pICH-M10990. The scFv genes were amplified by PCR with gene-specific forward primers (AA28-BsaI, 5'-TTT GGT CTC AAG GTA TGG CGG AGG TCC AGC TGC AGC AG; AB09-BsaI, 5'-TTT GGT CTC AAG GTA TGG CGC AGG TCC AAC TAC AGC; AB28-BsaI, 5'-TTT GGT CTC AAG GTA TGG CGC AGG TCC AGT TGC AGC; AD10BsaI, 5'-TTT GGT CTC AAG GTA TGG CGG AAG TGA AGC TGG TGG) and universal reverse primer KM2 (5'CTT TCC AGA CGT TAG TAA ATG), digested with BsaI and $B a m H I$ and cloned into the pICH-M10990 vector. The resulting constructs pICH-M1990-AA28, -AB09, -AB21, AB28, -AD10 were used for transformation of Agrobacterium tumefaciens strain GV3101 followed by selection of transformed agrobacteria on YEB-Carbenicillin-Rifampicillin (YEB-Rif-Carb) dishes. For agrobacteria-infiltration of the tobacco plants, $200 \mathrm{ml}$ of overnight grown scFv gene containing Agrobacterium cultures were sedimented by centrifugation $(6,000 \mathrm{~g}, 3 \mathrm{~min})$ and resuspended in $1 \mathrm{l}$ of $10 \mathrm{mM} \mathrm{MES}(\mathrm{pH} 5.5), 10 \mathrm{mM} \mathrm{MgSO}_{4}$. The resulting bacterial suspension was mixed with equal amounts of two agrobacteria strains transformed with plasmids pICH14011 (encodes DNA integrase) and pICH10570 (5'-provector for cytosolic expression), respectively, prepared in the same way. Greenhouse-grown plants of $N$. benthamiana were infiltrated by immersing the whole plant into $3 \mathrm{l}$ of the resulting agrobacteria suspension followed by vacuum application ( -0.8 bar) for 3 minutes. The gentle return to atmospheric pressure causes the agrobacterial suspension to spread inside the apoplastical system. The infiltrated $N$. benthamiana plants were further grown in the greenhouse. Maximum product accumulation was observed after 9-12 days, as determined by Western blot analysis of leaf discs. For large scale antibody production, the leaves of 12 plants (approx. $400 \mathrm{~g}$ ) were collected and homogenized in an extraction buffer (50 $\mathrm{mM} \mathrm{KH} \mathrm{PO}_{4} / \mathrm{K}_{2} \mathrm{HPO}_{4}, 100 \mathrm{mM}$ ascorbic acid) using a Waring Blender. The homogenate was cleared by filtration through Miracloth (Calbiochem, San Diego, CA) followed by centrifugation at $14,000 \mathrm{~g}$ and $4{ }^{\circ} \mathrm{C}$ for $20 \mathrm{~min}$. The antibody fragments were isolated from the clear supernatant by batch incubation with Ni-NTA His-bind resin (Novagen) and subsequent standard purification according to protocols from the manufacturer.

\section{Pea plant transformation and expression of scFvs in pea seeds}

For transformation of pea plants, an expression system based on the binary vector pPZP200 [62] with a seed specific promoter, regulation signals from Vicia faba [63-65] and a $35 \mathrm{~S}$ terminator of transcription from cauliflower mosaic virus (CaMV) [66] was used. The key features of the vector are outlined in Additional file 9. The scFv genes were cloned into the seed specific expression cassette of the pPZP200-USP+ plasmid using NcoI and BamHI restriction sites (Additional file 9) followed by electroporation into strain EHA105 of A. tumefaciens. For transformation, the fodder pea variety "Eiffel" was chosen. Pea transformation was carried out as described [67] with modifications [36]. In brief, immature pods were sterilized in $70 \%$ $(\mathrm{v} / \mathrm{v})$ ethanol $(1 \mathrm{~min})$ followed by $1 \%(\mathrm{w} / \mathrm{v})$ sodium hypochlorite $(20 \mathrm{~min})$ and three washes with sterile distilled water. Seeds were removed from the pods and the outer coats (testae) of the seeds were excised. Coatless seeds were pre-cultivated for 1 day in liquid $B_{5}$ h medium [68]. For preparation of explants, the root end of each segment was cut off and the epicotyl and the apical meristem regions were sliced transversely into 3-5 segments. Segments were then fully immersed in the agrobacterial suspension $\left(10^{8}\right.$ cells $\left./ \mathrm{ml}\right)$ for 30 to $40 \mathrm{~min}$. The suspension comprised two strains of transformed Agrobacterium, one carried the plasmid pPZP200-USP-scFv (see above) and the second one contained a binary vector pPZP-bar with the marker gene bar encoding phosphinotricin acetyltransferase (PAT), which confers resistance to gluphosinate ammonium (herbicide Basta). Wet segments were plated on $\mathrm{B}_{5} \mathrm{~h}$ medium and cultured at $21^{\circ} \mathrm{C}$ for 3-4 days with a $16 \mathrm{~h}$ photoperiod. After co-cultivation, explants were washed three to four times with sterile water. The callus induction medium and the shoot development were as described by Schroeder et al. [67]. When the developing shoots reached over $20 \mathrm{~mm}$ in length, they were grown on $10 \mathrm{mg} / \mathrm{L}$ phosphinotricin for some days. Resistant shoots were grafted onto the root stock of "Eiffel" seedlings in vitro. After 6-10 days, the plants were adapted to soil and grown up in a climatic chamber. When primary transformants $\left(\mathrm{F}_{0}\right)$ developed to a stage of 
4-6 normal nodes, leaflets were painted with a $0.5 \%(\mathrm{v} / \mathrm{v})$ watery solution of Basta (Sanofi-Aventis) on the upper side to determine the bar transgenic plants. Integration of the $\mathrm{scFv}$ transgene was checked by PCR in leaflet extracts using the primers scf-uni-up, 5'-AAA TTC ACC TTC TTC AAG C, and USP-do, 5'-AGG TGC ATG AAC GTC ACG TGG. The $\mathrm{F}_{0}$ plants were allowed to self-pollinate and 1020 seeds were analyzed for presence of the scFv gene by PCR and for expression of the scFv protein by SDS-PAGE and Western blot analysis. Using segregation analysis for both scFv and bar genes, non-coupled single insert lines for the scFv gene were determined. From all progeny of a single insert line, with the out-segregated bar gene, the homozygous state of the scFv gene was tested in the next $\left(\mathrm{F}_{2}\right)$ generation. Thus, co-transformation of both the bar and the scFv gene allowed selection of transgenic plants with no resistance (bar) gene. For estimation of the expression levels, the scFv antibody fragments were isolated from the pea seeds and purified. For isolation of the recombinant protein, the pea seeds were ground using a ball mill and the resulting pea flour was suspended in icecold extraction buffer containing $50 \mathrm{mM}$ Tris- $\mathrm{HCl}, 300$ $\mathrm{mM} \mathrm{NaCl}, 0.2 \%$ Tween-20, $\mathrm{pH} 7.4$, at a ratio of $1 / 20(\mathrm{w} /$ v). Extraction was performed at $4^{\circ} \mathrm{C}$ in three steps. After each step, the samples were centrifuged at 30,000 $\mathrm{g}$ and $4{ }^{\circ} \mathrm{C}$ for $30 \mathrm{~min}$. The supernatants were pooled and subjected to IMAC on Ni-NTA His-bond resin (Novagen) using the extraction buffer as loading and elution buffer, in the latter case supplemented with $500 \mathrm{mM}$ imidazole. The target protein was further purified using IEC and analyzed, as mentioned earlier for bacterial and tobacco scFv expression. Purified $\mathrm{scFv}$ was used as a standard for the quantification of antibody expression in pea seeds by ELISA using Eimeria oocyst extract as an antigen. Titration of scFv standard generated a calibration curve from which the amounts of active antibody in diluted pea seed extracts were deduced. Extracts from the pea seeds expressing $\mathrm{scFv}$ AB28 were prepared by grinding the seeds in a ball mill followed by soluble protein extraction from a defined amount of the powder in PBS containing $1 \mathrm{mM}$ PMSF. As a negative control, extracts from wild-type pea seeds prepared in the same way were used. Clear supernatants were applied to an ELISA plate in serial dilutions. Detection was performed using anti-penta-His antibody (Qiagen) followed by HRP-conjugated anti-mouse IgG (Sigma) and TMB as a substrate. Data were analyzed using the software Prism (GraphPad, San Diego, CA). The purity of the scFv standard, as determined by scanning a Coomassie-stained SDS-PAA gel, was considered in the calculations.

\section{Analysis of the proteolytic and $\mathrm{pH}$ stability in vitro} For analyses of the $\mathrm{pH}$ stability, commercially available standard buffers of pH 2-11 (Roth, Karlsruhe, Germany) were used. Analyses were performed by ELISA using plates coated with the diluted extract from E. tenella oocysts $(0.4$ $\mu \mathrm{g} /$ well). In the binding assays, the antibody fragments were diluted in buffers with different $\mathrm{pH}$, applied to the antigen-coated ELISA plate and incubated for $1 \mathrm{~h}$ at RT. For dissociation analyses, the antibody samples were applied in PBS/2\% BSA, pH 6.6, and after incubation (1 h at RT) and washing the buffer solution of a defined $\mathrm{pH}$ was added followed by $1 \mathrm{~h}$ incubation. In all cases, the bound antibody fragments were detected using antipenta-His antibody (Qiagen). For measuring the proteolytic stability, an "In vitro true digestibility" protocol from Ankom Technology (Macedon, NY) was used. For the experiments, chyme was taken from the small intestine of chickens, cleared by centrifugation and the resultant intestinal fluid was stored in aliquots at $-80^{\circ} \mathrm{C}$. Before start of the experiment, buffer solutions $\mathrm{A}$ and $\mathrm{B}$ were prepared according to the following recipes. The buffer solution $\mathrm{A}$ comprised $10 \mathrm{~g} / \mathrm{l} \mathrm{KH}_{2} \mathrm{PO}_{4}, 0.5 \mathrm{~g} / \mathrm{l} \mathrm{MgSO}_{4} \times 7 \mathrm{H}_{2} \mathrm{O}, 0.5 \mathrm{~g} / \mathrm{l}$ $\mathrm{NaCl}, 0.1 \mathrm{~g} / \mathrm{l} \mathrm{CaCl}{ }_{2} \times 2 \mathrm{H}_{2} \mathrm{O}$ and $0.5 \mathrm{~g} / \mathrm{l}$ urea (reagent grade). Respectively, the buffer solution $\mathrm{B}$ contained 15.0 $\mathrm{g} / \mathrm{l} \mathrm{Na} \mathrm{CO}_{3}$ and $1.0 \mathrm{~g} / \mathrm{l} \mathrm{Na} \mathrm{S}_{2} \times 9 \mathrm{H}_{2} \mathrm{O}$. The buffer solutions $\mathrm{A}$ and $\mathrm{B}$ were pre-warmed to $39^{\circ} \mathrm{C}$ and mixed in a ratio of $5 / 1$ to obtain $\mathrm{pH}$ 6.8. No further $\mathrm{pH}$ adjustment was necessary. The resulting buffer $\mathrm{AB}$ was used to prepare a series of $1 / 2$ dilutions of the chicken intestinal fluid. The antibody fragments were incubated with the dilutions of intestinal fluid at $37^{\circ} \mathrm{C}$ for $30 \mathrm{~min}$ on a rocking platform. The residual antigen-binding activity was measured by ELISA using plates coated with oocyst extract of E. tenella. In addition, protein degradation was monitored by SDSPAGE followed by Coomassie staining and by Western blot analysis with the anti-His-tag detection. For quantification of the results, the $E D_{50}$ values (effective dilution leading to $50 \%$ loss of activity) were deduced from the sigmoid ELISA curves [log(intestinal fluid dilution) vs. response (\% maximal binding)] by fitting them using a standard slope model of software Prism (GraphPad).

\section{Force-feeding animal trials}

Studies were performed using 10-day old non-sexed commercial Lohmann broiler chickens (type Ross) with an approx. weight of $100 \mathrm{~g}$ randomly divided into groups of 3-30 individuals (the cohort size varied in different studies). The chickens were orally infected with a single dose of E. tenella freshly prepared oocysts (20-500 oocysts per bird depending on the study). Force-feeding started one day before infection and continued for 8 consecutive days. Birds in the treatment groups received either $1 \mathrm{mg} \mathrm{scFv}$ isolated from tobacco leaves or transgenic pea seed flour in $1 \mathrm{ml}$ PBS a day via gavage. The chickens were force-fed three times daily. The maximum dose of pea seeds which could be safely administered to a 10-day old chicken was empirically determined as one pea seed a day or $1 / 3$ pea 
seed per administration. The pea flour was prepared from the antibody containing seeds using a ball mill and was suspended in phosphate buffer just before force-feeding. Based on the activity measurements in ELISA, the AB28 antibody content in pea seed was calculated as $1.76 \mathrm{~g}$ $\mathrm{scFv} / \mathrm{kg}$ seeds. Assuming the average weight of a pea seed as $0.3 \mathrm{~g}$, the pea flour-fed birds received the maximal possible dose of $0.5 \mathrm{mg}$ antibody per day (half the amount of administered purified scFv). As positive controls of infection, two animal groups were treated with the same quantities of material comprising the irrelevant BA11 antibody, either in the form of pea flour or as a soluble antibody isolated from the tobacco leaves. The negative control of infection group received heat inactivated oocysts. For comparison of anti-coccidial effect, one group received 1 $\mathrm{ml}$ of a $2.5 \%$ solution of the anti-coccidial drug Baycox ${ }^{\circledast}$ (Bayer HealthCare) in water. Baycox ${ }^{\circledast}$ is currently used to control Eimeria in commercial poultry farming. The treatment started one day before the infection and continued for 14 consecutive days. For all animals, fecal samples were collected before infection (to show whether the animals were already infected before the start of the experiment) and daily after infection. The oocyst counts were determined in all individual fecal samples and each sample was counted six times by two different persons. In addition, the chicken weights were controlled and recorded. At the end of each study, all birds were sacrificed and weighted according to the protocol. One individual of each group was subjected to necropsy. As measures of infection outcome, the sum of shed oocyst numbers at days of maximum oocyst release, 7 and 8 p.i., were used. To illustrate the specific effect of the anti-Eimeria treatment, the percentage of infection inhibition was calculated according to the following formula:

$\%$ infection inhibition $=(1-$ ratio of the average oocyst numbers shed by the treated animals and by birds in control group) $\times 100 \%$.

\section{Ad libitum feeding trials}

In a preliminary feeding experiment, twenty 9-day-old chickens were fed with normal feed $(\mathrm{n}=10)$ and with the feed premixed with 10\% BA11-transgenic pea shred $(\mathrm{n}=$ 10) for 8 days. The feed was weighed and reweighed every day, the body weight was recorded and the feces were collected on feeding days 3 and 7 . The antibody content in the fodder and in feces was controlled by the BA11-specific ELISA. In a high infection dose model, the broiler chickens were orally infected with individual doses of 2,500 freshly prepared oocysts. Three treatment cohorts were formed; each comprising 5-30 individually housed ten-day old chickens with average weight of $127.5 \mathrm{~g}$. For feeding, the usual chicken fodder was mixed with $10 \%$ pea shred derived either from AB28-expressing seeds (treatment group, $\mathrm{n}=30$ ) or from the wild-type pea (positive control of infection, $n=25$ ). For shredding, the pea seeds were coarsely ground with a centrifugal mill ZM
1000 (Retsch, Haan, Germany). The negative control group (control of spontaneous infection) comprised 5 birds which were not infected and received conventional fodder. Feeding started one day before the infection and continued for eight consecutive days. Adapted from the preliminary feeding experiment, the mean consumption of the scFv antibody was calculated as $35.63 \mathrm{mg}$ antibody/ $\mathrm{kg}$ body weight $\times$ day (Additional file 7 ). On the seventh day p.i., the chickens were sacrificed and the caecal lesion scores and the oocyst counts in caeca and feces were determined. The low infection dose model was designed to mimic the real situation in the barns for rearing commercial broilers where the chickens are spontaneously infected with the relatively low dosages of Eimeria oocysts. In this case, the feeding experiment was repeated under the same conditions, however, with the ten-fold lower infection doses, i.e. 250 oocysts per bird.

\section{Statistical analysis}

Data analyses were performed using the software Prism (GraphPad). All data were expressed as means \pm SEM values. Comparisons of the mean values were performed between the control and treatment groups using a one-tail unpaired $t$-test.

\section{Competing interests}

The authors declare that they have no competing interests.

\section{Authors' contributions}

$\mathrm{JZ}$ and $\mathrm{KZ}$ carried out library generation and screening. IS led generation of the transgenic pea plants. DJ carried out antibody characterization in vitro and supervised animal experiments. MG led gene cloning and plasmid constructions. SH led protein purification and stability analyses. JW and GG led the animal experiments. JM performed characterization of transgenic pea plants. DF initiated the work. SMK led the work and wrote the manuscript. All authors read and approved the final manuscript.

\section{Additional material}

\section{Additional file 1}

Characterization of AB28-transgenic pea lines.: The data provided represent PCR and Western blot analyses of $F_{0}$ and $F_{1}$ transgenic pea plants. Click here for file

[http://www.biomedcentral.com/content/supplementary/14726750-9-79-S1.pdf]

\section{Additional file 2}

Analyses of independent $A B 28 F_{0}$ pea lines. The data provided represent a summary of basta selection, PCR and Western blot analyses of independent $F_{0}$ transgenic pea lines.

Click here for file

[http://www.biomedcentral.com/content/supplementary/14726750-9-79-S2.pdf] 


\section{Additional file 3}

Analyses of $F_{1}$ seeds derived from $A B 28 F_{0}$ pea line 9 . The data provided represent a summary of PCR and Western blot analyses of $F_{1}$ seeds derived from $A B 28 F_{0}$ pea line 9.

Click here for file

[http://www.biomedcentral.com/content/supplementary/14726750-9-79-S3.pdf]

\section{Additional file 4}

Results of analyses of the progeny of $F_{1}$ lines $9 / 9,9 / 10,9 / 11$ and $9 /$ 13. The data provided represent a summary of Western blot analyses of $F_{2}$ seeds derived from different $A B 28 F_{1}$ lines.

Click here for file

[http://www.biomedcentral.com/content/supplementary/14726750-9-79-S4.pdf]

\section{Additional file 5}

Characterization of purified scFv AB28 produced in pea seeds. The data provided represent analysis of the molecular forms of pea-derived $s c F v$ and head-to-head comparison of the antigen-binding properties of the scFv $A B 28$ preparations isolated either from the tobacco leaves or from the transgenic pea seeds.

Click here for file

[http://www.biomedcentral.com/content/supplementary/14726750-9-79-S5.pdf]

\section{Additional file 6}

Preliminary ad libitum feeding experiment. The data provided represent analyses of the body weight and the feed consumption by chickens fed ad libitum with the fodder containing either transgenic or wt pea together with the assessment of shunning transgenic pea shred.

Click here for file

[http://www.biomedcentral.com/content/supplementary/14726750-9-79-S6.pdf]

\section{Additional file 7}

Feed consumption and antibody uptake in chickens. The data provided represent measured average feed consumption, body weight gains and calculated antibody uptake by chickens in a preliminary feeding experiment. Click here for file

[http://www.biomedcentral.com/content/supplementary/14726750-9-79-S7.pdf]

\section{Additional file 8}

List of expressed recombinant antigens of Eimeria tenella, their gene accession numbers and used PCR primers. The file provides information about generation of recombinant antigens used in the present study. Click here for file

[http://www.biomedcentral.com/content/supplementary/14726750-9-79-S8.pdf]

\section{Additional file 9}

Characteristics of the binary vector used for pea transformation. The file provides information about the genetic elements included into the binary vector used for pea transformation.

Click here for file

[http://www.biomedcentral.com/content/supplementary/14726750-9-79-S9.pdf]

\section{Acknowledgements}

We thank Prof. R. Entzeroth (TU Dresden) for providing us with the oocysts from the rodent Eimeria species, Prof. F. Tomley (IAH Compton) for oocysts of E. tenella (strain Houghton) and Prof. A. Daugschies (University of Leipzig) for the oocysts from avian Eimeria spp. different from $E$. tenella. We also thank Reda Khalafalla (University of Leipzig) for performing IFAT experiments.

\section{References}

I. Shirley MW, Smith AL, Tomley FM: The biology of avian Eimeria with an emphasis on their control by vaccination. Adv Parasitol 2005, 60:285-330.

2. Regulation (EC) No 1831/2003 of the European Parliament and of the Council of 22 September 2003 on additives for use in animal nutrition. Official Journal of the European Union 2003, L268:29-43.

3. Dalloul RA, Lillehoj HS: Recent advances in immunomodulation and vaccination strategies against coccidiosis. Avian Dis 2005, 49(I): $1-8$.

4. Shirley MW, Smith AL, Blake DP: Challenges in the successful control of the avian coccidia. Vaccine 2007, 25(30):5540-5547.

5. Fernando AM: Eimeria : infections of the intestine. In Coccidiosis of man and domestic animals Edited by: Long PL. Boca Raton: CRC Press, Inc; 1990:63-75.

6. Danforth HD: Use of monoclonal antibodies directed against Eimeria tenella sporozoites to determine stage specificity and in vitro effect on parasite penetration and development. Am / Vet Res 1983, 44(9): I722-I727.

7. Uchida T, Kikuchi K, Takano H, Ogimoto K, Nakai Y: Monoclonal antibodies inhibiting invasion of cultured cells by Eimeria tenella sporozoites. J Vet Med Sci 1997, 59(8):72I-723.

8. Augustine PC: Invasion of different cell types by sporozoites of Eimeria species and effects of monoclonal antibody I 209-C2 on invasion of cells by sporozoites of several apicomplexan parasites. J Eukaryot Microbiol 200I, 48(2): I77-I8I.

9. Wallach M, Pillemer G, Yarus S, Halabi A, Pugatsch T, Mencher D: Passive immunization of chickens against Eimeria maxima infection with a monoclonal antibody developed against a gametocyte antigen. Infect Immun I990, 58(2):557-562.

10. Karim MJ, Basak SC, Trees AJ: Characterization and immunoprotective properties of a monoclonal antibody against the major oocyst wall protein of Eimeria tenella. Infect Immun I996, 64(4): $1227-1232$

II. Labbe M, de Venevelles P, Girard-Misguich F, Bourdieu C, Guillaume A, Pery P: Eimeria tenella microneme protein Et MIC3: identification, localisation and role in host cell infection. Mol Biochem Parasitol 2005, I 40( I):43-53.

12. Brothers VM, Kuhn I, Paul LS, Gabe JD, Andrews WH, Sias SR, McCaman MT, Dragon EA, Files JG: Characterization of a surface antigen of Eimeria tenella sporozoites and synthesis from a cloned cDNA in Escherichia coli. Mol Biochem Parasitol 1988, 28(3):235-247.

13. Tomley FM, Clarke LE, Kawazoe U, Dijkema R, Kok J]: Sequence of the gene encoding an immunodominant microneme protein of Eimeria tenella. Mol Biochem Parasitol I99I, 49(2):277-288.

14. Tomley FM, Bumstead JM, Billington KJ, Dunn PP: Molecular cloning and characterization of a novel acidic microneme protein (Etmic-2) from the apicomplexan protozoan parasite, Eimeria tenella. Mol Biochem Parasitol 1996, 79(2):195-206.

15. Brown PJ, Billington KJ, Bumstead JM, Clark JD, Tomley FM: A microneme protein from Eimeria tenella with homology to the Apple domains of coagulation factor $X I$ and plasma prekallikrein. Mol Biochem Parasitol 2000, 107(I):91-102.

16. Jean L, Pery P, Dunn P, Bumstead J, Billington K, Ryan R, Tomley F Genomic organisation and developmentally regulated expression of an apicomplexan aspartyl proteinase. Gene 200I, 262(I-2): 129-136.

17. Binger MH, Hug D, Weber G, Schildknecht E, Humbelin M, Pasamontes $L$ : Cloning and characterization of a surface antigen of Eimeria tenella merozoites and expression using a recombinant vaccinia virus. Mol Biochem Parasitol 1993, 6 I (2): I79-187. 
18. Rosenberg B, Juckett DA, Aylsworth CF, Dimitrov NV, Ho SC, Judge JW, Kessel S, Quensen J, Wong KP, Zlatkin I, et al:: Protein from intestinal Eimeria protozoan stimulates IL- 12 release from dendritic cells, exhibits antitumor properties in vivo and is correlated with low intestinal tumorigenicity. Int J Cancer 2005, I I 4(5):756-765

19. Floss DM, Falkenburg D, Conrad U: Production of vaccines and therapeutic antibodies for veterinary applications in transgenic plants: an overview. Transgenic Res 2007, 16(3):315-332

20. Le Gall F, Kipriyanov SM, Moldenhauer G, Little M: Di-, tri- and tetrameric single chain $\mathrm{Fv}$ antibody fragments against human CD 19: effect of valency on cell binding. FEBS Lett 1999, 453:164-168.

21. Farner DS: The hydrogen ion concentration in avian digestive tracts. Poult Sci 1942, 2 I:445-449.

22. Augustine PC: Cell: sporozoite interactions and invasion by apicomplexan parasites of the genus Eimeria. Int $J$ Parasitol 200I, 3 I (I): I-8.

23. Conway DP, Dayton AD, McKenzie ME: Comparative testing of anticoccidials in broiler chickens: the role of coccidial lesion scores. Poult Sci 1999, 78(4):529-535.

24. Casadevall A: Antibody-based therapies as anti-infective agents. Expert Opin Investig Drugs 1998, 7(3):307-321.

25. Kipriyanov SM: Recombinant antibodies in infectious disease. Expert Opin Ther Patents 2004, I 4(2): I 35-I40.

26. Hiatt A, Cafferkey R, Bowdish K: Production of antibodies in transgenic plants. Nature 1989, 342(6245):76-78.

27. Abi-Ghanem D, Waghela SD, Caldwell DJ, Danforth HD, Berghman LR: Phage display selection and characterization of singlechain recombinant antibodies against Eimeria tenella sporozoites. Vet Immunol Immunopathol 2008, I 2 I ( I-2):58-67.

28. Wieland WH, Orzaez D, Lammers A, Parmentier HK, Schots A: Display and selection of chicken IgA Fab fragments. Vet Immunol Immunopathol 2006, II O( I-2): 129-140.

29. de Venevelles P, Chich JF, Faigle W, Loew D, Labbe M, Girard-Misguich F, Pery P: Towards a reference map of Eimeria tenella sporozoite proteins by two-dimensional electrophoresis and mass spectrometry. Int J Parasitol 2004, 34( I 2): | 32 | - I 33 |.

30. Jahn D, Matros A, Bakulina AY, Tiedemann J, Schubert U, Giersberg M, Haehnel S, Zoufal K, Mock HP, Kipriyanov SM: Model structure of the immunodominant surface antigen of Eimeria tenella identified as a target for sporozoite-neutralizing monoclonal antibody. Parasitol Res 2009, I05(3):655-668.

31. Giritch A, Marillonnet S, Engler C, van Eldik G, Botterman J, Klimyuk $V$, Gleba Y: Rapid high-yield expression of full-size IgG antibodies in plants coinfected with noncompeting viral vectors. Proc Natl Acad Sci USA 2006, 103(40): I 470 I-I 4706.

32. Bortesi L, Rossato M, Schuster F, Raven N, Stadlmann J, Avesani L, Falorni A, Bazzoni F, Bock R, Schillberg S, et al:: Viral and murine interleukin- 10 are correctly processed and retain their biological activity when produced in tobacco. BMC Biotechnol 2009, 9(I):22.

33. Fiedler U, Conrad U: High-level production and long-term storage of engineered antibodies in transgenic tobacco seeds. Biotechnology (N Y) 1995, I 3(10): 1090-1093.

34. Stoger E, Sack M, Nicholson L, Fischer R, Christou P: Recent progress in plantibody technology. Curr Pharm Des 2005, II(I9):2439-2457.

35. Stoger E, Ma JK, Fischer R, Christou P: Sowing the seeds of success: pharmaceutical proteins from plants. Curr Opin Biotechnol 2005, 16(2):167-173.

36. Saalbach I, Giersberg M, Conrad U: High-level expression of a single-chain Fv fragment (scFv) antibody in transgenic pea seeds. I Plant Physiol 200I, I 58(4):529-533.

37. Ma JK, Barros E, Bock R, Christou P, Dale PJ, Dix PJ, Fischer R, Irwin J, Mahoney R, Pezzotti M, et al.: Molecular farming for new drugs and vaccines. Current perspectives on the production of pharmaceuticals in transgenic plants. EMBO Rep 2005, 6(7):593-599.

38. Laskowski M, Laskowski M Jr: Naturally occurring trypsin inhibitors. Adv Protein Chem 1954, 9:203-242.

39. Qi RF, Song ZW, Chi CW: Structural features and molecular evolution of Bowman-Birk protease inhibitors and their potential application. Acta Biochim Biophys Sin (Shanghai) 2005 37(5):283-292.
40. Losso JN: The biochemical and functional food properties of the Bowman-Birk inhibitor. Crit Rev Food Sci Nutr 2008, 48(I):94-118.

4I. Wörn A, Plückthun A: Stability engineering of antibody singlechain Fv fragments. J Mol Biol 200I, 305(5):989-10I0.

42. Binz HK, Amstutz P, Plückthun A: Engineering novel binding proteins from nonimmunoglobulin domains. Nat Biotechnol 2005, 23(10): $1257-1268$.

43. Polonelli L, Ponton J, Elguezabal N, Moragues MD, Casoli C, Pilotti E, Ronzi P, Dobroff AS, Rodrigues EG, Juliano MA, et al: Antibody complementarity-determining regions (CDRs) can display differential antimicrobial, antiviral and antitumor activities. PLoS ONE 2008, 3(6):e237I.

44. Raether W, Hofmann J, Uphoff M: In vitro cultivation of avian Eimeria species: Eimeria tenella. In Guidelines on techniques in coccidiosis research Edited by: Eckert J, Braun R, Shirley MW, Coudert P. Luxembourg: The European Commission DGXII; 1995:79-89.

45. Breitling F, Moosmayer D, Brocks B, Dübel S: Construction of scFv from hybridoma by two-step-cloning. In Antibody Engineering Edited by: Kontermann R, Dübel S. Berlin-Heidelberg: Springer Verlag; 200I:4I-55

46. McCafferty J, Johnson KS: Construction and screening of antibody display libraries. In Phage display of peptides and proteins: $A$ laboratory manual Edited by: Kay BK, Winter J, McCafferty J. San Diego: Academic Press; 1996:79-III.

47. Schwarz M, Röttgen P, Takada Y, Le Gall F, Knackmuss S, Bassler N, Büttner C, Little M, Bode C, Peter K: Single-chain antibodies for the conformation-specific blockade of activated platelet integrin $\alpha \mathrm{llb} \beta 3$ designed by subtractive selection from naive human phage libraries. FASEB J 2004, I 8( I 4): I 704-I 706.

48. Welschof M, Terness P, Kipriyanov SM, Stanescu D, Breitling F, Dörsam $H$, Dübel $S$, Little $M$, Opelz $G$ : The antigen-binding domain of a human IgG-anti-F(ab') ${ }_{2}$ autoantibody. Proc Natl Acad Sci USA 1997, 94(5): 1902-1907.

49. Dübel S, Breitling F, Fuchs P, Braunagel M, Klewinghaus I, Little M: A family of vectors for surface display and production of antibodies. Gene 1993, I 28(I):97-I0I.

50. Shirley MW: Maintenance in animal hosts Eimeria species and strains of chicken. In Guidelines on techniques in coccidiosis research Edited by: Eckert J, Braun R, Shirley MW, Coudert P. Luxembourg: The European Commission DGXII; 1 995: I-24.

5I. Bradford MM: A rapid and sensitive method for the quantitation of microgram quantities of protein utilizing the principle of protein-dye binding. Anal Biochem 1976, 72:248-254.

52. Schubert U, Fuchs J, Zimmermann J, Jahn D, Zoufal K: Extracellular calcium deficiency and ryanodine inhibit Eimeria tenella sporozoite invasion in vitro. Parasitol Res 2005, 97(I):59-62.

53. Refega S, Girard-Misguich F, Bourdieu C, Pery P, Labbe M: Gene discovery in Eimeria tenella by immunoscreening cDNA expression libraries of sporozoites and schizonts with chicken intestinal antibodies. Vet Parasitol 2003, I I3(I): 19-33.

54. Le Gall F, Reusch U, Moldenhauer G, Little M, Kipriyanov SM: Immunosuppressive properties of anti-CD3 single-chain Fv and diabody. J Immunol Methods 2004, 285( I): I I I- I 27.

55. Kipriyanov SM: High-level periplasmic expression and purification of scFvs. Methods Mol Biol 2002, I78:333-34I.

56. Sambrook J, Fritsch EF, Maniatis T: Molecular Cloning: A Laboratory Manual. 2nd edition. Cold Spring Harbor, NY: Cold Spring Harbor Laboratory Press; 1989.

57. Tomley $\mathrm{F}$ : Techniques for isolation and characterization of apical organelles from Eimeria tenella sporozoites. Methods 1997, 13(2): 17|-176.

58. Shirley MW: Cryopreservation of avian Eimeria stages. In Guidelines on techniques in coccidiosis research Edited by: Eckert J, Braun R, Shirley MW, Coudert P. Luxembourg: The European Commission DGXII; 1995:95-96.

59. Aden DP, Fogel A, Plotkin S, Damjanov I, Knowles BB: Controlled synthesis of $\mathrm{HBsAg}$ in a differentiated human liver carcinoma-derived cell line. Nature 1979, 282(5739):615-616.

60. Gleba Y, Marillonnet S, Klimyuk V: Engineering viral expression vectors for plants: the 'full virus' and the 'deconstructed virus' strategies. Curr Opin Plant Biol 2004, 7(2): I82-188.

6I. Marillonnet S, Giritch A, Gils M, Kandzia R, Klimyuk V, Gleba Y: In planta engineering of viral RNA replicons: efficient assembly by recombination of DNA modules delivered by Agrobacterium. Proc Natl Acad Sci USA 2004, I 0 I( I 8):6852-6857. 
62. Hajdukiewicz P, Svab Z, Maliga P: The small, versatile pPZP family of Agrobacterium binary vectors for plant transformation. Plant Mol Biol 1994, 25(6):989-994.

63. Bäumlein H, Nagy I, Villarroel R, Inze D, Wobus U: Cis-analysis of a seed protein gene promoter: the conservative $R Y$ repeat CATGCATG within the legumin box is essential for tissuespecific expression of a legumin gene. Plant J 1992, 2(2):233-239.

64. Bäumlein H, Boerjan W, Nagy I, Bassuner R, Van Montagu M, Inze D, Wobus U: A novel seed protein gene from Vicia faba is developmentally regulated in transgenic tobacco and Arabidopsis plants. Mol Gen Genet I99I, 225(3):459-467.

65. Zakharov A, Giersberg M, Hosein F, Melzer M, Muntz K, Saalbach I: Seed-specific promoters direct gene expression in non-seed tissue. J Exp Bot 2004, 55(402): I463-I47I.

66. Pietrzak M, Shillito RD, Hohn T, Potrykus I: Expression in plants of two bacterial antibiotic resistance genes after protoplast transformation with a new plant expression vector. Nucleic Acids Res 1986, I 4(14):5857-5868.

67. Schroeder HE, Schotz AH, Wardley-Richardson T, Spencer D, Higgins $\mathrm{T}$ : Transformation and regeneration of two cultivars of pea (Pisum sativum L.). Plant Physiol 1993, I 0 I (3):75I-757.

68. Brown DCW, Atanassov A: Role of genetic background in somatic embryogenesis in Medicago. Plant Cell Tissue Organ Cult 1985, 4: III-122.

Publish with Bio Med Central and every scientist can read your work free of charge

"BioMed Central will be the most significant development for disseminating the results of biomedical research in our lifetime. "

Sir Paul Nurse, Cancer Research UK

Your research papers will be:

- available free of charge to the entire biomedical community

- peer reviewed and published immediately upon acceptance

- cited in PubMed and archived on PubMed Central

- yours - you keep the copyright
BiolMedcentral 